\title{
A long noncoding RNA promotes cellulase expression in Trichoderma reesei
}

\author{
Petra Till ${ }^{1,2}$, Marion E. Pucher ${ }^{2}$, Robert L. Mach² and Astrid R. Mach-Aigner ${ }^{1,2^{*}}$ (D)
}

\begin{abstract}
Background: Due to its capability to secrete large quantities of plant biomass degrading enzymes (PBDE), Trichoderma reesei is widely applied for industrial purposes. In nature, expression of PBDE is efficiently regulated in this fungus. Several factors involved in this regulatory network have been identified. However, most of them are transcription factors. Long noncoding RNAs (IncRNAs) emerged as common players acting on epigenetic or transcriptional regulation in several eukaryotic organisms. To date, no IncRNA has been described in filamentous fungi.

Results: A IncRNA termed HAX1 was identified in T. reesei QM9414. In this study, it was characterized and evidence for its regulatory impact on cellulase expression was provided. Interestingly, different versions of HAX1 were identified in different strains (namely, QM6a, QM9414, and Rut-C30), varying in terms of RNA length. Remarkably, considerable longer variants of this IncRNA are present in hypercellulolytic strains compared to the wild-type strain QM6a. Based on these results, a correlation between RNA length and the functional impact of HAX1 on PBDE expression was supposed. This assumption was verified by overexpressing the most abundant HAX1 versions identified in QM6a, QM9414, and Rut-C30. Such HAX1 overexpression on the one hand was suitable for regaining the function in hax1 disruption strains, and on the other hand resulted in notably higher cellulase activities in QM6a, especially by the expression of longer HAX1 versions.
\end{abstract}

Conclusion: With HAX1, for the first time the regulatory role of a IncRNA in filamentous fungi was uncovered. Besides this, a new player involved in the complex regulation of PBDE expression in T. reesei was identified. Due to its enhancing effect on cellulase activity, HAX1 was shown to be not only interesting for basic research, but also a promising candidate for expanding the set of biotechnological tools for industrial application of $T$. reesei.

Keywords: Trichoderma reesei, Hypocrea jecorina, Filamentous fungi, Long noncoding RNA, HAX1, Cellulases

\section{Background}

The filamentous fungus Trichoderma reesei (teleomorph Hypocrea jecorina [1], phylum Ascomycota) is one of the most potent producers of plant biomass degrading enzymes (PBDE) used in industrial applications. Due to its saprophytic life style, it secretes large quantities of cellulases, hemicellulases, and other glycoside hydrolases such as $\beta$-glucosidases and xylosidases [2]. The dominating ones are the major cellobiohydrolases CBHI and CBHII (EC.3.2.1.91) [3] as well as the main

\footnotetext{
${ }^{*}$ Correspondence: astrid.mach-aigner@tuwien.ac.at

${ }^{2}$ Institute of Chemical, Environmental and Bioscience Engineering, TU

Wien, Gumpendorfer Str. 1a, 1060 Vienna, Austria

Full list of author information is available at the end of the article
}

endo- $\beta-1,4-x y l a n a s e s, X Y N I$ and XYNII (EC.3.2.1.8) [4]. Industrial demand for these enzymes is given in food, feed [5], and textile [6] industries, paper and pulp fabrication [7], as well as production of biofuels [8-10]. In nature, production of cellulases and xylanases is tightly regulated in this fungus. Thus, understanding the processes involved in the regulatory network with the purpose of strain improvement are in the focus of past and present scientific research [11-15].

The wild-type strain QM6a is a good producer of PBDE under inducing conditions [16]. Yet, when more easily utilizable carbon sources, such as glucose, are available, the production of cellulases and xylanases is turned down by carbon catabolite repression (CCR) [17, 18]. Two 
strains derived from QM6a via random mutagenesis and selection for increased PBDE expression are QM9414 and Rut-C30 [19]. Rut-C30 is characterized by strongly increased cellulase activities and partial carbon catabolite derepression and thus became the progenitor of most industrial strains [19-21].

The reason for the partial carbon catabolite derepressed phenotype of Rut-C30 is the production of a truncated version of the main regulatory factor acting on CCR, the Carbon Catabolite Repressor 1 (Cre1) [22]. Besides Cre1, the main regulatory protein of PBDE expression in all $T$. reesei strains is the essential transactivator Xylanase regulator 1 (Xyr1). A deletion of this transactivator results in a complete shutdown of all major cellulases and hemicellulases $[23,24]$. Other proteins functioning as regulators of PBDE expression, are Ace1 [25], Ace2 [26], Ace3 [27], Cre2 [28], PAC1 [29], and the recently reported BglR [30]. However, all of them are modulating the expression of their target genes by operating as transcription factors.

Another widespread mechanism for specific regulation of gene expression in eukaryotes that has gained in importance more and more in the past decades is accomplished by noncoding RNAs (ncRNAs). A large group of functional ncRNAs are the long noncoding RNAs (lncRNAs). They are mainly defined upon their size of $>200 \mathrm{nt}$ and by their functional, but non-protein coding nature [31-35]. As lncRNAs identified in different organisms obviously do not share a common evolutionary origin, their functional roles, mechanistic strategies, and features are very diverse [36]. They might possess a poly(A)-tail and could get processed by splicing, but both is not necessarily the case. However, as they act directly as RNAs in a functional way, they are usually characterized by distinct secondary structure formation [37, 38]. Given a regulatory role, the expression of the lncRNAs is often tightly regulated either in a tissue- or in a condition-specific manner, and generally low compared to mRNAs [31, 34, 39]. LncRNAs are present in several eukaryotes such as plants [40], invertebrates [41, 42], or amphibians [43]. Yet, the most prominent examples of lncRNAs have been described in mammals and are predominantly affecting epigenetic regulation. Among those are HOTAIR, a transregulator of the Hox cluster that is widely involved in gene silencing [44]; and the central factor for X-chromosomal inactivation, Xist [45]. In addition, in yeast, lncRNAs causing transcriptional gene silencing by acting on the chromatin status and epigenetic marks have been identified [36]. Two more accurately described lncRNAs in yeast are SRG1 [46] and an $f b p 1$-proximal element involved in glucose starvation [47], both of them functioning in cis in a transcription-interfering manner. Compared to mammalian lncRNAs, examples in yeast are rare and usually neither named nor investigated in detail. Considering the impressively high level of nc transcripts compared to protein encoding genes $[34,35,48,49]$ and the increasing number of lncRNAs found throughout the whole eukaryotic domain, lncRNAs are likely to play a role in all eukaryotic organisms. However, to our knowledge, hitherto no lncRNAs have been identified in filamentous fungi.

During this study, a lncRNA in the industrially applied fungus $T$. reese $i$ was discovered. Evidence for its impact on regulation of PBDE expression was provided. Variation of this lncRNA in length in moderate cellulase producing compared to overproducing $T$. reesei strains was shown, hence indicating evolutionary improvement of the lncRNA during strain genesis. As a final outcome of this study, this lncRNA is not only the first description of such in filamentous fungi, but also highlighted as an interesting player in a complex regulatory network and as a promising biotechnological tool for strain improvement in T. reesei.

\section{Results}

An undescribed gene locus influences cellulase expression in T. reesei QM9414

Commonly, phenotypic investigation of strains generated by targeted mutagenesis requires a reference strain carrying solely the marker gene. For this reason, the amdS marker gene enabling utilization of acetamide [50] was randomly integrated into the genome of $T$. reesei QM9414 (ATCC 26921). To our surprise, subsequent characterization studies of the 18 resulting reference strains revealed certain phenotypic characteristics of three candidates. Enzymatic assays of liquid fungal cultures grown on xylan showed that $\beta$-glucosidase activity is significantly lower in these strains compared to the parent strain QM9414, i.e, about 59\% (Fig. 1A). Moreover, also the cellulase activity was reduced about $50 \%$ in cultures that were induced on lactose (Fig. 1B).

Since enzymes acting on the degradation of cellulose were affected in these strains, a crucial role of the disrupted genomic region in regulation of cellulose degradation was hypothesized. Hence, the site targeted by the amdS marker gene was identified via inverse PCR. Interestingly, sequence analysis revealed that-although a random integration strategy was followed-the amdS gene was integrated at the same locus in all three strains. This finding was verified by Southern blot analysis applying a locus-specific probe (Fig. 1C). The reason for the preference of this target site remained unclear; however, the experiment resulted in the identification of a hitherto undescribed region of the genome probably involved in regulation of PBDE expression. 

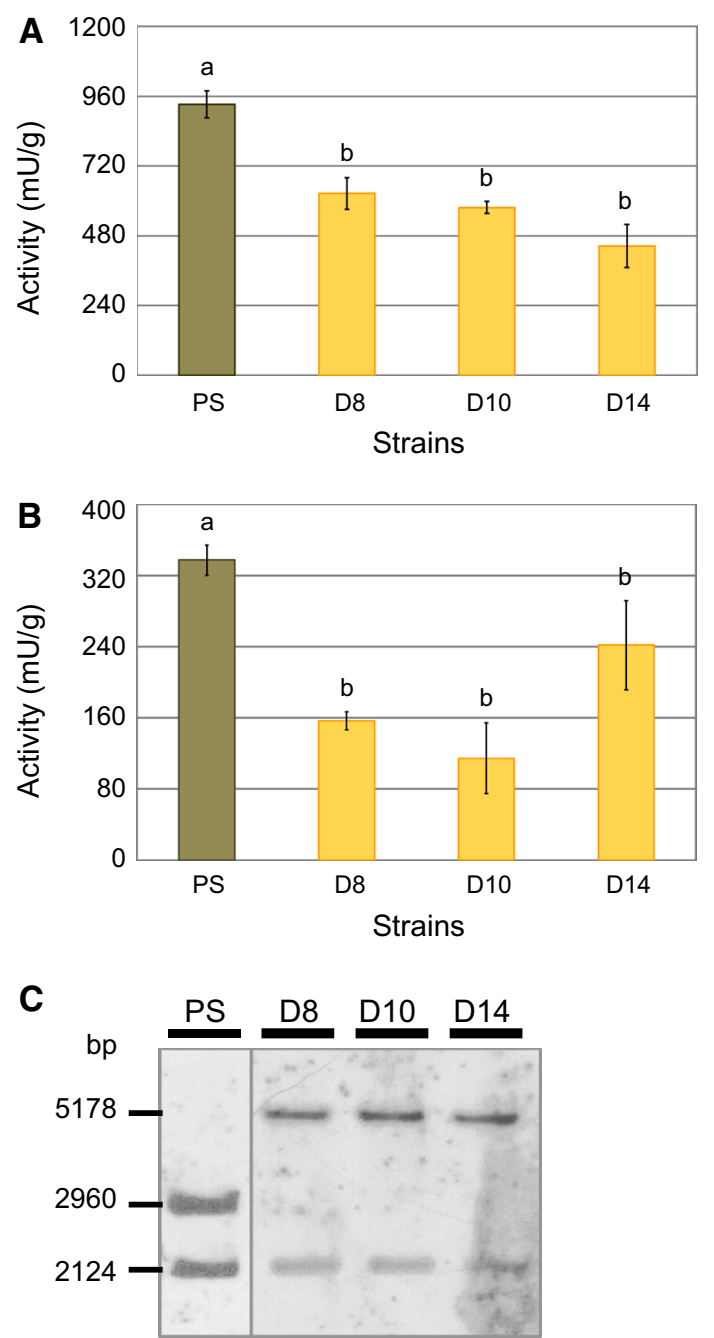

Fig. 1 Phenotype and genotype of Trichoderma reesei QM9414 disruption mutants. The $\beta$-glucosidase activities $\mathbf{A}$ and cellulase activities $\mathbf{B}$ of three $T$. reesei mutant strains bearing a randomly integrated amdS marker gene (i.e., QM9414_Dhax1_8 (D8), _10 (D10) and _14 (D14); yellow bars) and their parent strain QM9414 (PS; brown bars). Strains were cultivated on xylan for $66 \mathrm{~h}$ (for $\beta-$ glucosidase assays) and on lactose for $48 \mathrm{~h}$ (for cellulase assays). Reaction with the Azo-cellazyme $\mathrm{C}$ tablet for detection of cellulase activity was performed for 90 min. Enzymatic activities are given in $\mu$ and referred to biomass (dry weight). The values are means of biological triplicates. The error bars depict the standard deviation and different letters denote statistical difference among compared data employing ANOVA $(P<0.05)$. C Southern blot analysis using Sacll-digested chromosomal DNA of the investigated strains and a locus-specific probe. Expected signals are at $5178 \mathrm{bp}$ (from integration of the amdS cassette at this locus), $2960 \mathrm{bp}$ (for the native locus) and $2124 \mathrm{bp}$ (for a sequence downstream of the amdS targeted locus)

\section{Discovery of $H A X 1$, a long noncoding RNA}

Based on the genome sequence of T. reesei QM6a accessible in the Joint Genome Institute (JGI) database [51], the site targeted by the amdS marker gene was assigned to an intergenic region on scaffold 14. It is flanked upstream by a 2-isopropylmalate synthase (Protein ID 79495), and downstream by a poorly described coding region referred to as "hypothetical protein" (Protein ID 108999); both of them are minus-strand encoded (Fig. 2a). Remarkably, the targeted region seems to lack any homologues. Genome conservation analysis displayed in Fig. 2a indicates only slight sequence similarities between $T$. reesei to a noncoding region on the Trichoderma virens genome and no homolog regions in Nectria haematococca or Trichoderma atroviridae.

To find out if the observed cellulase-depleted phenotype of the disruption strains is caused by the interruption of the undescribed genomic region or rather by any impact of the integrated amdS cassette on expression of the adjacent genes, transcript analysis of the genes encoding the hypothetical protein and the 2-isopropylmalate synthase was performed. For this purpose, the three mutants and their parent strain QM9414 were pre-grown and replaced to a cellulase inducing and a repressing condition and compared to a replacement to a medium without carbon source. As given in an additional file, transcript levels of both adjacent genes are the same in QM9414 and the mutant strains (Additional file 1). Thus, an effect of amdS integration on the cellulase activity by altering the expression of the upstream- or downstream genes can be excluded. In addition, a particular effect of the used marker system was ruled out by generation of other disruption strains bearing the $h p h$ gene (encoding hygromycin B resistance) instead of the amdS gene at the same locus.

As a consequence, the interrupted region itself was supposed to encode a gene involved in regulation of cellulose degrading enzymes. Hence, gene prediction was performed applying different gene prediction models for in silico analyses of the locus. One used algorithm provided by the gene prediction web server AUGUSTUS [52] assigned the sequence as coding for a gene. An illustration of the predicted, $782 \mathrm{bp}$-long structural gene is shown in Fig. 2b. It contains two putative introns at 113-201 and 269-325 bp from the ATG. At the 5'-end (untranslated- and coding region), a sequence element rich in Xyr1-binding sites is present.

Transcript formation of this potential gene further referred to as "hax1" was analysed via reverse transcription quantitative PCR (RT-qPCR) (Fig. 2c). To cover the whole structural gene, transcript levels of five overlapping fragments (each of them approximately 200-300 bp in length) were determined in separate PCRs. In general, transcript levels of hax 1 were quite low. However, transcript formation could be verified for the $5^{\prime}$-end of the gene (PCR 2) as well as for the $5^{\prime}$-upstream region (PCR 1). Lower levels could also be detected in case of 


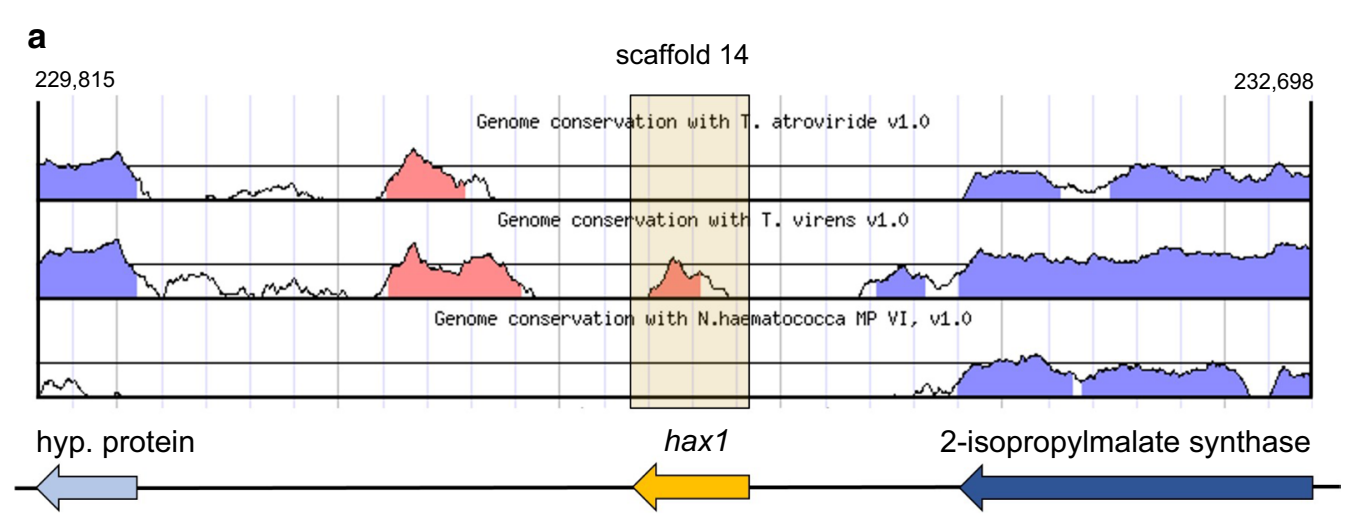

b
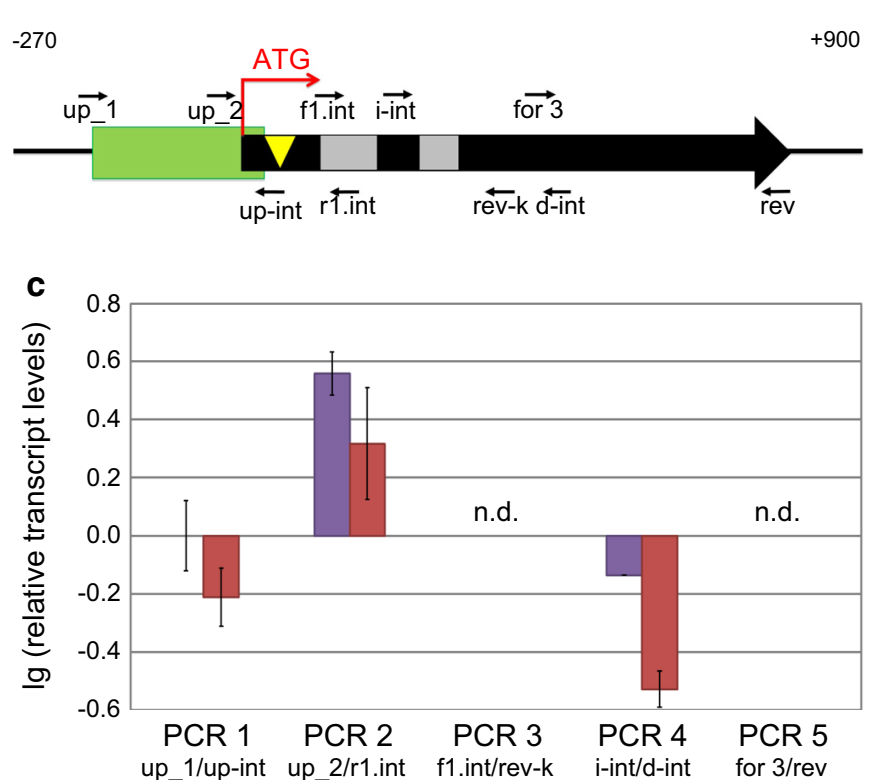

d

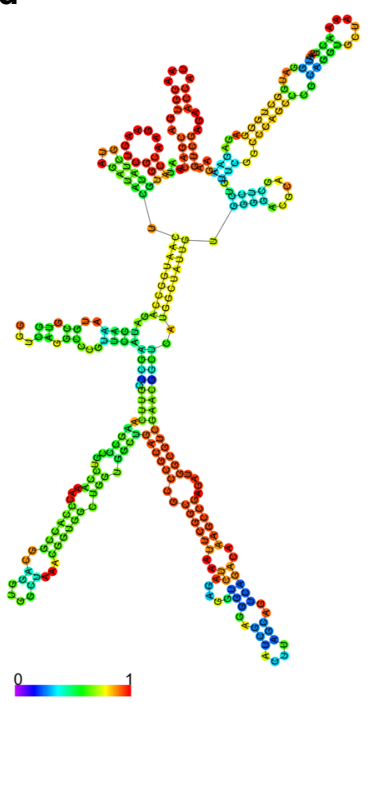

Fig. 2 Properties of the hax 1 locus and its encoded regulatory factor. a Locus targeted by amdS integration in QM9414_Dhax 1 strains and its genetic environment according to JGI genome database of Trichoderma reesei QM6a v2.0. The targeted locus hax1, the downstream coding region referred to as "hypothetical protein" (hyp. protein) and the upstream gene encoding 2-isopropylmalate synthase are illustrated as yellow, light and dark blue arrows, respectively. b Schematic illustration of the 782 bp hax 1 structural gene (black arrow) predicted by the web server AUGUSTUS. Start codon (ATG, red arrow), introns (grey boxes), site targeted by integration of the amdS cassette (yellow triangle), 5'-region rich in Xyr1-binding sites (green box) and position of the primers used for transcript analysis (thin, black arrows) are indicated. Numbers on top indicate position from ATG in base pairs. c Transcript levels of hax1 in QM9414 that was pre-grown and transferred to medium without carbon source (violet bars) or $1 \%(\mathrm{w} / \mathrm{V}$ ) D-glucose (red bars) for $3 \mathrm{~h}$. Indicated primer pairs were used for PCR 1, 2, 3, 4, and 5, respectively. Transcript levels were normalized to act and sar1, refer to PCR 1 (no carbon source) and are given in logarithmic scale (lg). Analysis was performed in technical triplicates. Error bars indicate standard deviations. Up_1, up-hax1 for_1; up-int, hax1 rev up-Intron; up_2, up-hax1 for_2; r1.int, hax1 rev 1.Intron; f1.int, hax1 for_1.Intron; rev-k, hax1 rev kurz; i-int, hax1 for_inter-Intron; d-int, hax1 rev_down-intron; for 3, hax1 for_3; rev, hax1 rev; n.d., not detectable. d In silico structure prediction of the IncRNA HAX1 with minimized free energy. Structure stability is increasing from violet, blue, green and yellow to red

the central region including the second intron (PCR 4), but no amplicons resulted for the central region comprising both introns (PCR 3) and for the 3 '-end (PCR 5). This analysis suggested that not the whole predicted gene, but mainly, the $5^{\prime}$-terminal region is transcribed. Therefore, the generation of the potential translation product Hax1 is rather unlikely. This assumption is further supported by the detection of a transcript in the $5^{\prime}$-region that comprises at least a part of the putative first intron (Fig. 2c, PCR 2), suggesting that posttranscriptional splicing events do not take place. In addition, the analysis of the codon usage [53] of the protein encoding sequence displayed in an additional file, neither supports the presence of a typical $T$. reesei gene, nor does it indicate an origin in 
lateral gene transfer from another organism (Additional file 2). Finally, a protein BLAST of the deduced amino acid sequence as well as a nucleotide BLAST of the hax 1 gene to the pool of coding elements gathered in the NCBI archive [54] did not result in any hits.

Altogether, there are no indications for the generation of a translation product, even if transcript formation could be verified. These findings suggest that the region targeted by amdS insertion is a ncRNA. To concretely define the boundaries of this RNA, $3^{\prime}$ and $5^{\prime}$ rapid amplification of cDNA ends (RACE) were performed. $5^{\prime}$ RACE revealed a frequent occurrence of a $5^{\prime}$-end 127 nt upstream of the ATG. Classical $3^{\prime}$ RACE applying the supplied Oligo dT-Anchor primer for reverse transcription did not yield any specific products. Yet, enrichment of $H A X 1$ from QM9414 RNA extracts using a biotinylated hax1-specific DNA probe and streptavidinlinked magnetic beads followed by poly(A)-tailing and $3^{\prime}$ RACE defined the major $3^{\prime}$-end to be located $173 \mathrm{nt}$ downstream of the ATG. This end could also be verified via $H A X 1$ enrichment and $3^{\prime}$ RACE, skipping the additional poly(A)-tailing step.

The resulting RNA is 299 nt in length, hence classifying it as a lncRNA. Since reverse transcription using the Oligo dT-Anchor primer for $3^{\prime}$ RACE analysis gave a specific product, $H A X 1$ is supposed to be $3^{\prime}$ polyadenylated. According to in silico structure prediction using the RNAfold Web server [55], it is characterized by a distinct secondary structure formation (Fig. 2d), which is a typical property of lncRNAs. To this end, the function of the lncRNA $H A X 1$ as a regulatory factor of PBDE expression was supposed.

\section{No phenotypic effects by hax1-disruption in the $T$. reesei wild-type strain QM6a}

As the disruption of hax1 led to a decreased cellulase expression in T. reesei QM9414, the same locus was disrupted in the wild-type strain QM6a by directed integration of the amdS gene. For this purpose, a disruption cassette comprising the $5^{\prime}$ - and $3^{\prime}$-flanking regions of the targeted site for integration of the amdS marker gene was produced. Protoplast transformation led to integration of the cassette into the genome of QM6a_stmus53 by homologous recombination. Four of the obtained disruption strains (QM6a_Dhax1_1,_2,_3, and _8) were chosen for phenotypic analysis. Again, strains were grown in liquid media containing lactose for induction of cellulase expression. The detected enzymatic activities in the resulting culture supernatants are given in Fig. 3. Surprisingly, in $H A X 1$ disrupted strains, cellulase activity was not reduced compared to the parent strain. To learn if this apparent lack of the characteristic phenotype is caused by a failure in transcript formation, RT-qPCR

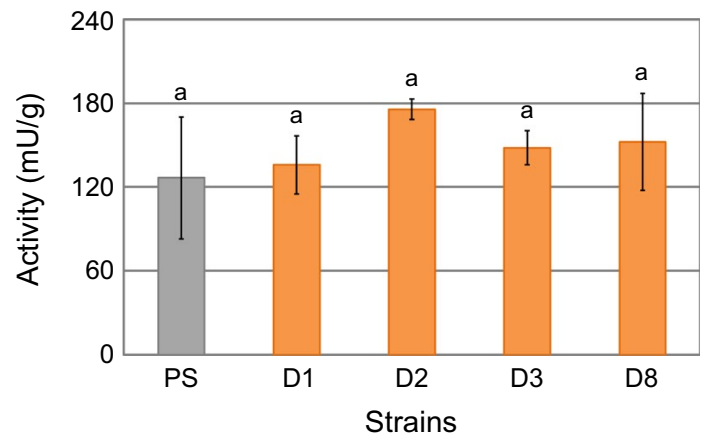

Fig. 3 Cellulase activities of Trichoderma reesei QM6a_Dhax1 strains. QM6a_Dhax1 strains (D1, D2, D3, and D8; orange bars) and the parent strain QM6a_Atmus53 (PS; grey bar) were cultivated on lactose for $70 \mathrm{~h}$. Reaction with the Azo-Cellazyme C tablet for detection of cellulase activity was performed for 30 min. Enzymatic activities measured in the resulting supernatants are given in $\mu$ and referred to the biomass (dry weight). The values are means of biological triplicates. The error bars depict the standard deviation and different letters denote statistical difference among compared data employing ANOVA $(P<0.05)$

was performed. Amplicons using primers for PCR 2 (compare Fig. 2c) appeared after 28.3 cycles for cultures grown without carbon source, and 27.3 cycles for cultivation on $1 \% \mathrm{D}$-glucose, yielding average relative logarithmic transcript levels of 0.00 and 0.26 , respectively (see Additional file 3). These results demonstrate that, though transcript formation of hax 1 is given, the disruption of the locus had no effect on cellulase activity in case of the T. reesei wild-type strain QM6a. This raised the question if the role of the lncRNA $H A X 1$ might differ in the various strains of $T$. reesei.

\section{HAX1-length differs in different $T$. reesei strains}

As the resulting phenotype from the disruption of haxl indicated differences in various $T$. reesei strains, $5^{\prime}$ and $3^{\prime}$ RACE for $H A X 1$ was performed also in QM6a and Rut-C30. In both strains, $3^{\prime}$ RACE of HAX1 enriched from total RNA extracts verified the major $3^{\prime}$-end located $173 \mathrm{nt}$ downstream of the ATG, as defined before in QM9414. In contrast, the $5^{\prime}$-ends of the lncRNA turned out to be different in the strains. Whereas in QM9414, the major transcription start point was located $127 \mathrm{nt}$ upstream of the ATG, the most frequent $5^{\prime}$-end in QM6a was found 89/90 nt upstream of the ATG yielding a shorter transcript of $262 \mathrm{nt}$ in length. Only rarely, longer versions of $H A X 1$ (5'-end up to $-151 \mathrm{nt}$ ) were detected in QM6a, just as in QM9414. However, the highest abundance of long $H A X 1$ versions was found in the hypercellulolytic strain Rut-C30. There, the major $5^{\prime}$-end is located $-255 \mathrm{nt}$ of the ATG, albeit also in this case 
sporadically both longer (e.g., $-266 \mathrm{nt}$ ) and shorter (e.g., $-160 \mathrm{nt}$ ) versions were detected. This allows the possibility that not only the presence or the absence of $H A X 1$, but also a particular length can have a distinct regulatory impact. To learn if the different levels of cellulase activities could result from variations in the genomic organisation of the hax 1 locus rather than from $H A X 1$ length, the locus was sequenced in QM9414 and Rut-C30 and aligned to the sequence of QM6a. Both the sequence of the locus and the position relative to the adjacent genes were the same in all three strains (see Additional file 4), hence pointing to the transcript length as the important difference. Provided that the RNA length is a relevant property, we investigated if it might be determined by a difference in RNA stability of the $H A X 1$ versions. We could not observe degradation of any of the three $H A X 1$ versions up to $2 \mathrm{~h}$ after the transcription was stopped by the transcription inhibitor DRB (see Additional file 5). Thus, we exclude that the different lengths are a result of different stability, but rather of a different transcription start site.

The respective ends of the major $H A X 1$ versions identified in QM6a (hax1 $\left.1_{\mathrm{QM6a}}\right)$, QM9414 (hax $\left.1_{\mathrm{QM} 9414}\right)$, and Rut-C30 ( $\operatorname{Lax1}_{\mathrm{Rut}-\mathrm{C} 30}$ ) are marked on the schematic illustration in Fig. 4a. Abundance of the transcript versions in the different strains was tested by a qualitative PCR using cDNAs as templates and a limited number of cycles to enable an estimation of the quantities. As expected, $h a x 1_{\mathrm{QM} 6 \mathrm{a}}$ can be detected in all three strains, whereas the longer transcript versions $h a x 1_{\mathrm{QM} 9414}$ and $\operatorname{haxl}_{\text {Rut-C30 }}$ are mainly amplified from QM9414 and Rut-C30, respectively (Fig. 4b). Levels of hax $1_{\text {Rut-C30 }}$ were very low, giving only faint bands. Albeit this version is detectable in all three strains, it is predominantly detectable in samples derived from Rut-C30 compared to QM6a and QM9414, especially on sophorose as a cellulase inducing condition (Fig. 4b).

To estimate if $H A X 1_{\mathrm{QM} 6 \mathrm{a}}, H A X 1_{\mathrm{QM} 9414}$, and $H A X 1_{\text {Rut- }}$ C30 could fulfil different functions, in silico structure prediction was performed using the RNAfold Web server [55]. The secondary structures of minimized free energy are displayed in Fig. 4c. All of them are characterized by a lncRNA-typical formation of duplexed RNA. They are composed of a stem forming a hairpin-rich region at one end and splitting into two stem loops on the other end. In $H A X 1_{\mathrm{QM} 6 \mathrm{a}}$ and $H A X 1_{\mathrm{QM} 9414,}$ most of the hairpins are quite well conserved; however, in $H A X 1_{\mathrm{QM} 9414}$, an additional hairpin is breaking the structure of the main stem. For $H A X 1_{\text {Rut-C30, }}$ in contrast, the overall structure is rather different. In fact, the three versions of $H A X 1$ only have one stem loop in common. This supports the assumption that those RNAs can act differently.

\section{Overexpression of hax 1 rescues the cellulase-depleted phenotype in QM9414_Dhax1 strains}

To understand the distinct impact of $H A X 1_{\mathrm{QM} 6 \mathrm{a}}$, $H A X 1_{\mathrm{QM} 9414}$, and $H A X 1_{\mathrm{Rut}-\mathrm{C} 30}$, all three versions were overexpressed in two of the QM9414 HAX1 mutant strains (i.e., QM9414_Dhax1_8 and_14). As an initial control experiment, the absence of the three hax1 versions was tested in the two recipient strains by RT-qPCR (see Additional file 6). The expression constructs comprise the native bgl1 ( $\beta$-glucosidase 1) promoter [56] and the respective version of haxl, which are flanked by the pyr4 (encoding the orotidine $5^{\prime}$-phosphate decarboxylase) upstream- and downstream regions. Consequently, homologous integration at the pyr4 locus resulted in a 5-fluoroorotic acid (5-FOA) resistant and uridine auxotroph phenotype. The usage of the bgll promoter, of which the transcription start point is known, secured that only hax 1 is expressed. For characterization, the overexpression strains and the two parent strains were cultivated in liquid culture on $1 \%$ lactose for $72 \mathrm{~h}$. Supernatant samples were taken after $37,48,60$, and $72 \mathrm{~h}$. Cellulase activity was increased in all overexpression strains compared to the parent strains after $48 \mathrm{~h}$ of cultivation (Fig. 5A). Moreover, differences resulting from overexpression of the distinct haxl version became evident: overexpression of $\operatorname{hax} 1_{\mathrm{QM} 6 \mathrm{a}}$ has less impact on cellulase activity than $\operatorname{hax} 1_{\mathrm{QM} 9414}$, and overexpression of $h a x 1_{\text {Rut- }}$ C30 yielded the highest cellulase activity. Even though the results slightly differed between the two strain lines, exactly the same trend could be found. As shown for QM9414_Dhax1_14, this trend remains constant during the whole time course of the experiment (Fig. 5B) and can also be detected at the final time point if referred to the biomass (Fig. 5C).

\section{Overexpression of hax 1 enhances cellulase activity in $T$. reesei QM6a}

To learn if the expression of $\operatorname{hax} 1_{\mathrm{QM6a}}$, $\operatorname{hax} 1_{\mathrm{QM} 9414}$, and $h a x 1_{\text {Rut-C30 }}$ can change cellulase expression in the T. reesei wild-type strain QM6a, the before used constructs were introduced into QM6a_dtmus53 and integrated at the pyr4 locus by homologous recombination. Subsequently, the resulting strains overexpressing either of the hax 1 versions as well as the parent strain (QM6a_dtmus53) and a reference strain

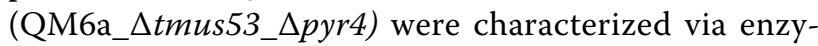
matic assays. Again, a time course experiment was performed growing the strains on $1 \%$ lactose for cellulase induction. The enzymatic activities of samples prepared 


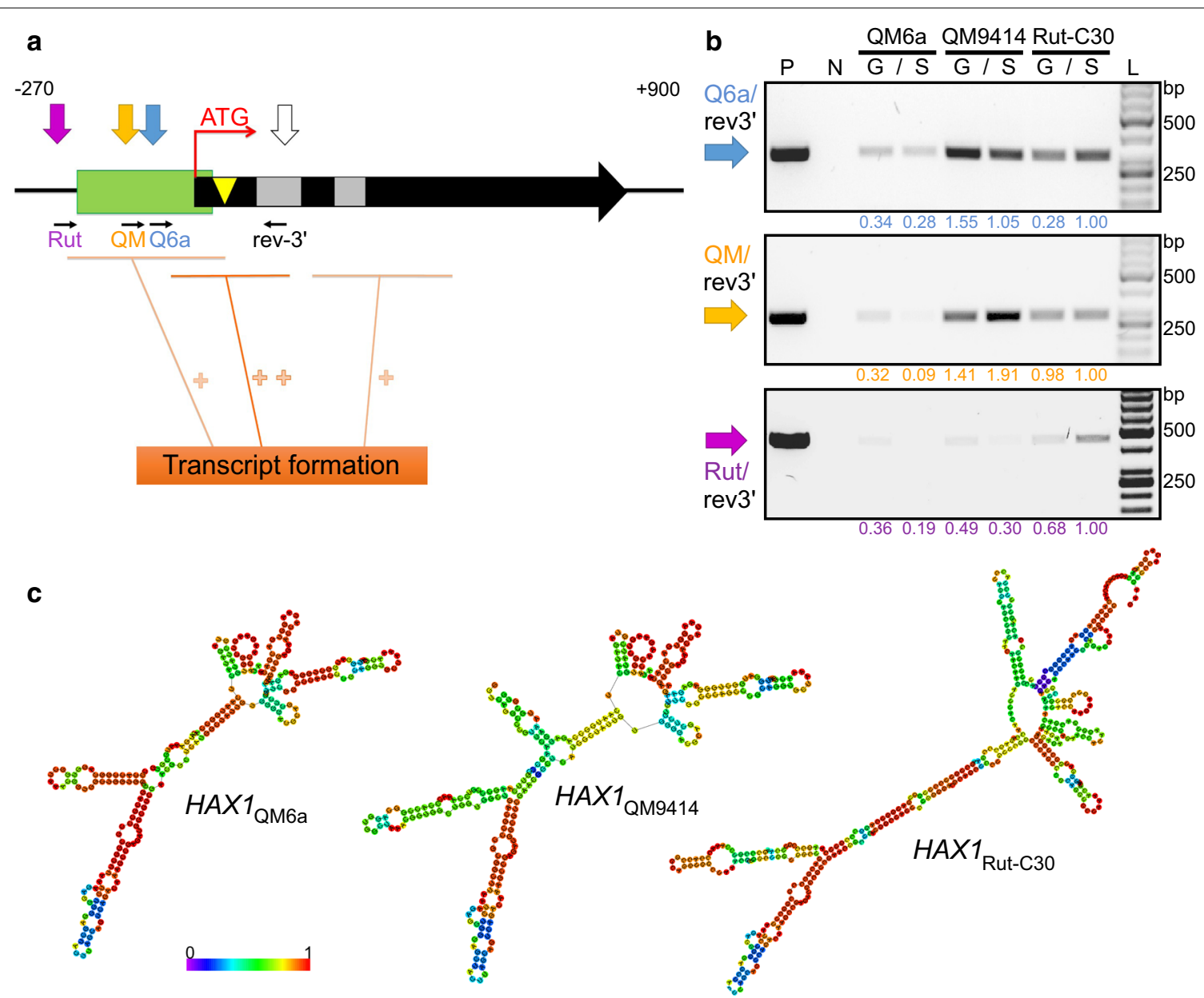

Fig. 4 Analyses of HAX1 versions in T. reesei QM6a, QM9414 and Rut-C30. a Schematic illustration of the 782 bp hax1 structural gene (black arrow). Start codon (ATG, red arrow), introns (grey boxes), site targeted by integration of the amdS cassette (yellow triangle) and $5^{\prime}$-region rich in Xyr1-binding sites (green box) are indicated. Previously detected transcripts (Fig. 2c; PCR 1, PCR 2 and PCR 4) are illustrated by orange lines; lower or higher transcript levels are indicated by one or two plus symbols, respectively. Approximate positions of the $3^{\prime}$-end (white arrow) and 5'-ends of $\mathrm{HAX}_{\mathrm{QM6a}}$ (blue arrow), $\mathrm{HAX}_{\mathrm{QM} 9414}$ (yellow arrow) and $\mathrm{HAX}_{\mathrm{Rut}-\mathrm{C30}}$ (purple arrow) defined by RACE-PCR are marked. Positions of the primers used for amplification of the respective hax1 versions displayed in $\mathbf{b}$ are given as thin, black arrows. Rev-3', hax1 rev_3'QM6a; Q6a, hax1 for_QM6a_Bcul; QM, hax1 for_QM9414_BCul; Rut, hax1 for_Rut-C30_Bcul. Numbers on top indicate position from ATG in base pairs. b Gel electrophoreses of PCRs of the HAX1 versions in different T. reesei strains using CDNAs of QM6a, QM9414 and Rut-C30 as templates. Strains were pre-grown and transferred to medium with $1 \%(\mathrm{~W} / \mathrm{v})$ D-glucose (G) or $1.5 \mathrm{mM}$ sophorose (S). Used primer pairs are indicated on the left (i.e, the PCR for detecting hax $1_{\mathrm{QM}} \mathrm{Ca}$ is analysed in gel on top; for detecting hax ${ }_{\mathrm{QM} 9414}$ in the middle gel; and for detecting hax $1_{\text {Rut-C30 }}$ in the gel at the bottom). The strength of each band was quantified using Image Lab version 5.2 and related to the sample of Rut-C30 on sophorose (numbers are given below the respective

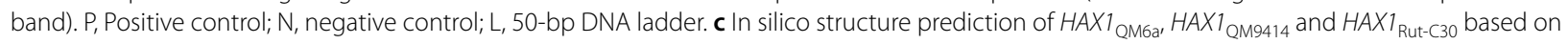
RACE-defined $3^{\prime}$ - and $5^{\prime}$-ends. Structures of minimized free energy are displayed. The stability is increasing from violet, blue, green, and yellow to red

after $37,48,60$, and $72 \mathrm{~h}$ were determined. As observed before for hax1 overexpression in QM9414_Dhax1, the cellulase activities are importantly higher in all QM6a OEhax 1 strains compared to the parent and reference strain (Fig. 6A). Again, depending on the expressed version of $H A X 1$, different levels of cellulase activities were achieved: the overexpression of the longest $H A X 1$ version identified in Rut-C30 had the largest impact on cellulase activity. This is true for different times of cultivation as well as for values referred to the final biomass
(Fig. 6A, B). Interestingly, in the case of the wild-type strain QM6a, the effect of overexpressing hax1 was even more pronounced than in the case of QM9414. For example, the cellulase activities of strains overexpressing hax1 $1_{\text {Rut-C30 }}$ in QM9414_Dhax1 were threefold higher compared to the parent strain, whereas in QM6a_OEhax $1_{\text {Rut-C30, they were even fivefold }}$ increased. Conclusively, the introduction of additional hax 1 copies (especially the long version $h a x 1_{\text {Rut-C30 }}$ ) did not only restore cellulase expression in hax1-disrupted 


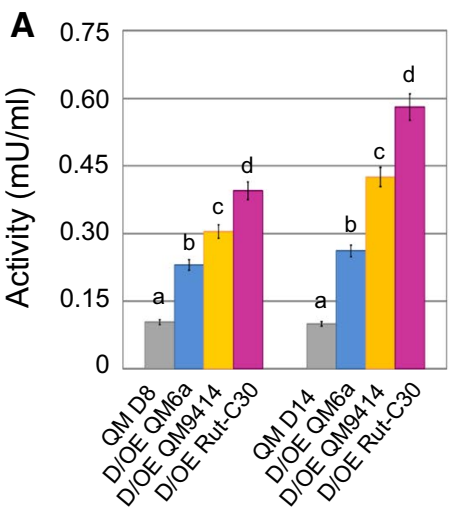

Strains

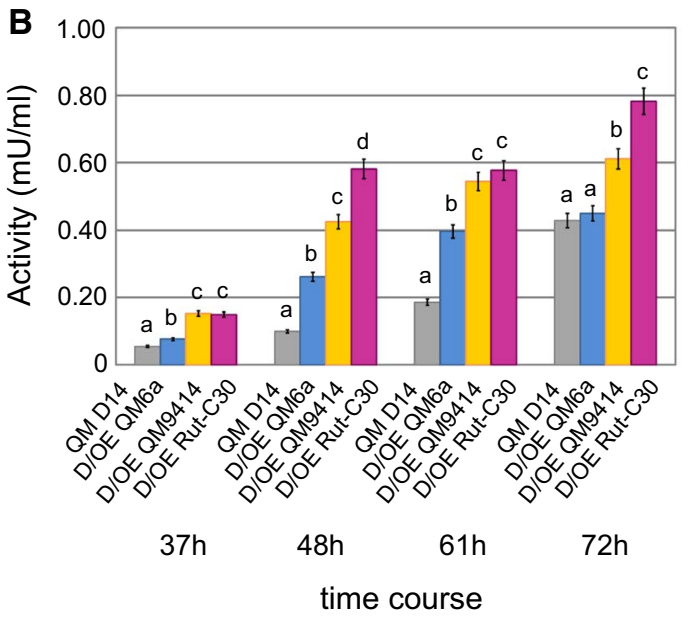

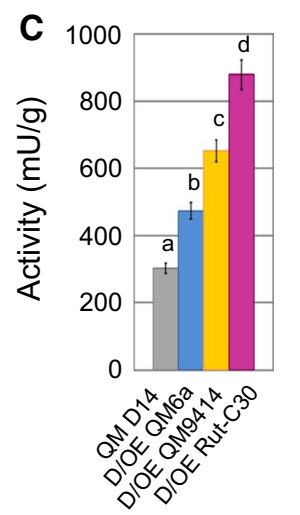

Strains

Fig. 5 Cellulase activities of complemented QM9414_Dhax1 strains. Cultivation of QM9414_Dhax1 strains overexpressing either hax 1 OM6a (D/OE

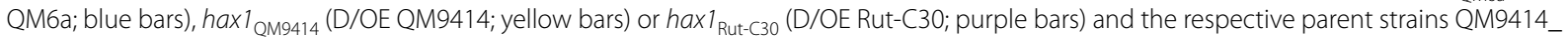
Dhax1_8 and_14 (QM D8 and QM D14; grey bars) was performed on lactose for $72 \mathrm{~h}$. A Cellulase activities of parent strains and the corresponding overexpression strains after cultivation on lactose for $48 \mathrm{~h}$ are given in reference to the culture volume. $\mathbf{B}$ Cellulase activities of the parent strain QM9414_Dhax1_14 and the corresponding overexpression strains after cultivation on lactose for 37, 48, 61 and $72 \mathrm{~h}$ are given in reference to the culture volume. c Cellulase activities of the parent strain QM9414_Dhax1_14 and the corresponding overexpression strains after cultivation on lactose for $72 \mathrm{~h}$ are given in reference to the final biomass (dry weight). Reaction with the Azo-Cellazyme $\mathrm{C}$ tablet for detection of cellulase activity was performed for $2 \mathrm{~h}, 45,20$, and 20 min for the timepoints 37, 48, 61, and $72 \mathrm{~h}$, respectively. All values are means of biological triplicates. The error bars depict the standard deviation and different letters denote statistical difference among compared data employing ANOVA $(P<0.05)$
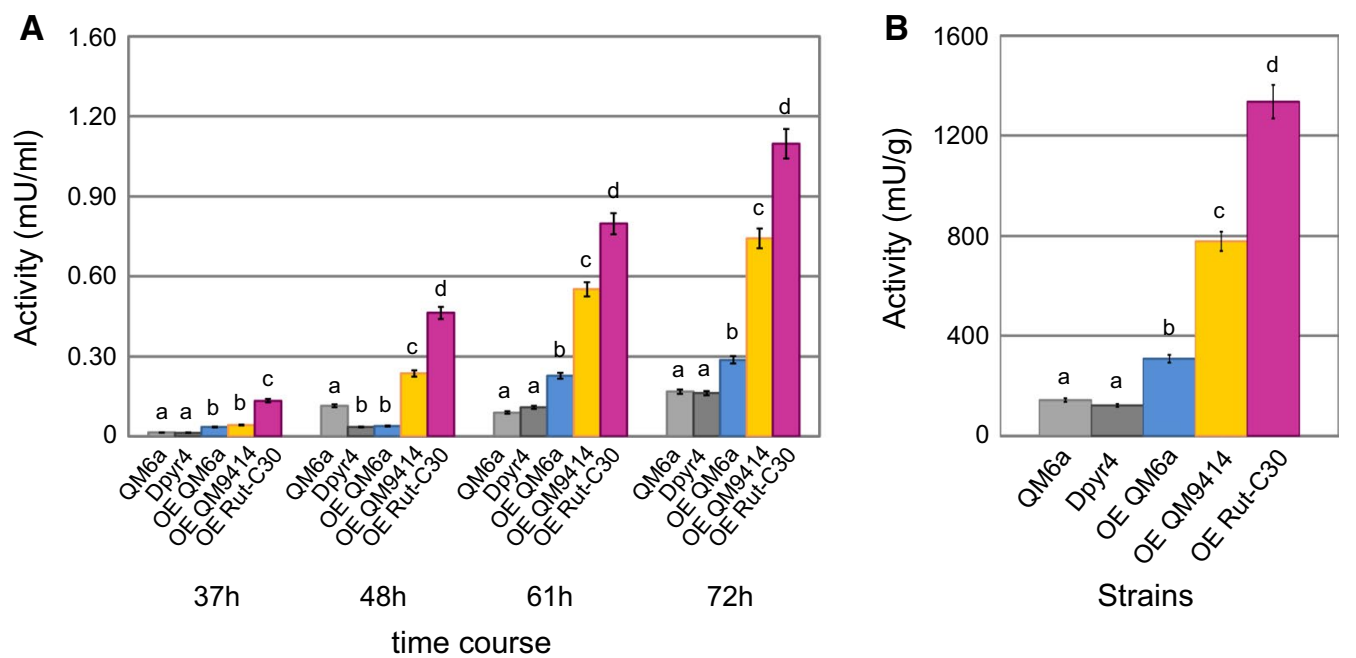

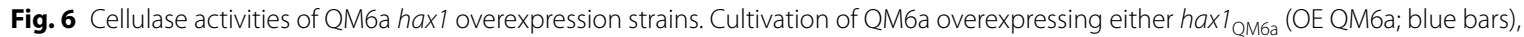

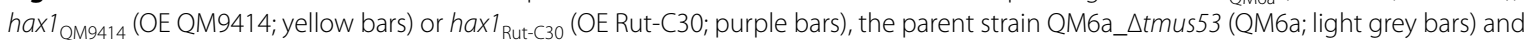

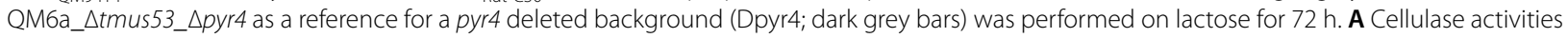
of the overexpression and reference strains after cultivation on lactose for 37, 48,61 and $72 \mathrm{~h}$ are given in reference to the culture volume. B Cellulase activities of the overexpression and reference strains after cultivation on lactose for $72 \mathrm{~h}$ are given in reference to the final biomass (dry weight). Reaction with the Azo-Cellazyme C tablet for detection of cellulase activity was performed for 5, 3, $2 \mathrm{~h}$ and 75 min for the timepoints 37 , 48,61 , and $72 \mathrm{~h}$, respectively. All values are means of biological triplicates. The error bars depict the standard deviation and different letters denote statistical difference among compared data employing ANOVA $(P<0.05)$ 
strains, but it suggests itself as a tool for enhancing cellulase production.

\section{Discussion}

In the last years, lncRNAs emerged as crucial factors acting on transcriptional and epigenetic regulation in eukaryotes. Within the fungal kingdom, the literature is only available about lncRNAs identified in yeast $[36,46,47]$. Thus, to our knowledge, the lncRNA HAX1 characterized in this study is the first one described in a filamentous fungus. As a prime representative of this category, its features and mechanistic strategies are of special importance. In course of this work, HAX1 was found to be $3^{\prime}$ polyadenylated, yet there is no information about the presence or absence of a $5^{\prime}$ methylguanosine cap. Anyhow, those are variable characteristic of lncRNAs [37, 38]. A more distinctive feature is the formation of pronounced secondary structures $[37,38]$. Based on in silico structure prediction, this is true for $H A X 1$ and presumably facilitates its specific regulatory activities. Moreover, the transcript level of haxl was very low, suggesting that this transcript is not translated into a protein.

Another interesting point that turned out during studies on HAX1 is its exclusive presence in T. reesei. This is in contrast to the main regulatory proteins of the T. reese $i$ PBDE expression, which are well conserved in filamentous fungi. For example homologues of the transactivator Xyr1 have been studied and described in several other fungi such as Neurospora crassa, Aspergillus spp., Fusarium spp., or Magnaporthe oryzae [57, 58], and proteins resembling Cre1 in its function and sequence are even found in yeast [59]. Yet, other than for transcription factors, poor conservation is common for lncRNAs [32, 36, $60,61]$. Thus, this finding further supports the conclusion that the factor encoded by hax 1 indeed is a regulatory RNA rather than a protein.

Considering the fact that $H A X 1$ has an impact on PBDE expression, one outcome concerning the mechanism of $H A X 1$ is that it acts on distal targets rather than simply interfering with the transcriptional machinery in cis. Given that no targets proximal to the hax1 locus are known to be regulated by $H A X 1$ strengthens this assumption. Moreover, a trans mode of action is supported, because ectopic overexpression of HAX1 results in a distinct phenotype (i.e., increased cellulase activity). Both trans and cis operation modes are common for lncRNAs [32, 62]. Yet, the possibility to act on distal targets strongly extends the potential sphere of influence.

Maybe, the most remarkable finding about $H A X 1$ and its mechanistic strategy is that obviously different dominant versions of it are present in moderate cellulase producing and overproducing $T$. reesei strains. The HAX1 versions differ in length, resulting from variation of the transcriptional start site. The overall longest versions of HAX1 have been identified in the industrial progenitor strain Rut-C30. Comparing QM9414 and QM6a, again, the longer version is present in the hyper-producing strain QM9414. This fits to the different effects observed for disruption of hax1 in QM9414 and in QM6a. In QM9414 hax1 disrupted strains, cellulase activity was lower compared to the reference strain, whereas in QM6a, disruption of hax1 had no phenotypic effects. Since $H A X 1$ versions identified in Rut-C30 are even longer, an additional enhancing effect on cellulase activity could be supposed. This assumption was supported by the overexpression of the three major HAX1 versions $\left(\right.$ hax $1_{\mathrm{QM6a}}$, hax $1_{\mathrm{QM} 9414,}$ and $\operatorname{hax} 1_{\mathrm{Rut}-\mathrm{C} 30}$ ) in QM6a, which led to an enhancing effect on cellulase activity with increasing $H A X 1$ length. Anyhow, it has to be considered that differences in RNA length impact RNA folding of HAX1.

A slightly similar example for production of different versions of a nc transcript is the vertebrate lncRNA $E v f-2$, which is generated from $E v f-1$ by alternative splicing. For both ncRNAs, the expression is developmentally regulated; however, only Evf-2 acts on neuronal differentiation in a regulatory manner by cooperating with Dlx-2 $[63,64]$. In contrast to this, all three versions of $H A X 1$ have a functional role. The mechanism of lncRNA length variation in different strains as described herein for $T$. reesei is also remarkable on an evolutionary point of view, regarding the genesis of cellulase overproducing $T$. reese $i$ strains like QM9414 and Rut-C30. Current data are also raising speculations about the nature of $H A X 1$ in industrial strains. In this regard, $H A X 1$ versions with greater impact on PBDE expression might be discovered. Consequently, this brings outstanding potential for utilization of $H A X 1$ as a tool for targeted strain improvement.

Anyway, more work has to be done to shed light on the complex strategy of alternated lncRNA production, the detailed mode of action of $H A X 1$ and a possible interplay with other factors involved in regulation of PBDE expression in T. reesei.

\section{Conclusion}

During this study, HAX1 was discovered and characterized as the first lncRNA in filamentous fungi. As such, $H A X 1$ is an outstanding example in the literature and of particular importance for basic research. Moreover, it is interesting from an evolutionary point of view as it is only present in $T$. reesei, but not in other, even closely related microorganisms. This makes $H A X 1$ a protruding regulatory element beside the well-conserved central transcription factors Xyr1 and Cre1. The mechanism described for $H A X 1$ is unique as it can result in different regulatory outputs. Based on the results presented in this 
study, HAX1 can be considered as a potential target for directed engineering to promote productivity of industrially applied $T$. reesei strains.

\section{Methods}

\section{Fungal strains and growth conditions}

Throughout this study, the $T$. reesei strains listed in Table 1 were used. All strains were maintained on malt extract (MEX) agar at $30^{\circ} \mathrm{C}$. If applicable, 5-FOA or uridine was added to final concentrations of $1.5 \mathrm{mg} / \mathrm{ml}$ or $5 \mathrm{mM}$, respectively.

For carbon source replacement experiments, mycelia were pre-cultured in $250 \mathrm{ml}$ of Mandels-Andreotti (MA) medium [65] supplemented with $1 \%(\mathrm{w} / \mathrm{v})$ glycerol as the sole carbon source on a rotary shaker $(180 \mathrm{rpm})$ at $30^{\circ} \mathrm{C}$ for $24 \mathrm{~h}$. A total of $10^{9}$ conidia per litre (final concentration) were used as the inoculum. Pre-grown mycelia were washed, and equal amounts were resuspended in $20 \mathrm{ml}$ MA medium without any carbon source (reference condition) or MA medium containing $1 \%(\mathrm{w} / \mathrm{v}) \mathrm{D}$-glucose or $1.5 \mathrm{mM}$ sophorose. Samples were taken after $3 \mathrm{~h}$ of incubation from three biological replicates.

For direct cultivations for the $\beta$-glucosidase assays, $30 \mathrm{ml} \mathrm{MA}$ medium containing $1 \%(\mathrm{w} / \mathrm{v})$ oat spelt xylan (Sigma-Aldrich, St. Louis, MO, USA) were inoculated with $10^{8}$ conidia per litre (final concentration) and incubated at $30{ }^{\circ} \mathrm{C}$ and $250 \mathrm{rpm}$ for $66 \mathrm{~h}$. For direct cultivations for cellulase assays, the Dhaxl strains were incubated for $48 \mathrm{~h}$ and $70 \mathrm{~h}$ at $30{ }^{\circ} \mathrm{C}$ and $180 \mathrm{rpm}$ in $100 \mathrm{ml} \mathrm{MA}$ medium containing $1 \%(\mathrm{w} / \mathrm{v}) \alpha$-D-lactose inoculated with $10^{9}$ conidia per litre (final concentration). For time course experiments, the OEhax1 strains were incubated for $72 \mathrm{~h}$ and $10 \mathrm{ml}$ samples were taken after 37, 48 , and $61 \mathrm{~h}$.

\section{Plasmid construction}

Construction of p5-A-3 used for disruption of the hax1 locus in the T. reesei wild-type strain QM6a was done as follows. The 452 bp $5^{\prime}$ - and the 1066 bp $3^{\prime}$-flanks of the targeted site for insertion of the amdS marker gene were amplified using the primers locus $5^{\prime}$ for Sall/locus $5^{\prime}$ rev HindIII and locus $3^{\prime}$ for Acc65I/locus 3'rev XbaI, respectively, and cloned into pGEM-T (Promega, Madison, WI, USA). Subsequently, the $5^{\prime}$-fragment was released with HindIII and SalI and ligated into the vector pAMDS (a derivate of pUC19 containing the $3864 \mathrm{bp}$ amdS gene [23]) digested with the same enzymes. Finally, the 3 '-fragment released with $A c c 65 \mathrm{I}$ and $\mathrm{Xba \textrm {I }}$ was introduced into the plasmid p5-A resulting from the first cloning step, downstream of the amdS marker gene. The final construct

Table 1 Fungal strains used in this study

\begin{tabular}{|c|c|c|c|c|}
\hline Name & Abbreviation & Employment & Phenotype $^{a}$ & Source \\
\hline QM6a & & RACE & & ATCC 13631 \\
\hline QM6a_Atmus53 & & Recipient strain, RACE & & {$[70]$} \\
\hline QM6a_stmus53_spyr4 & & $\begin{array}{l}\text { Reference strain } \\
\text { ( } \Delta \text { pyr4 background) }\end{array}$ & $\begin{array}{l}\mathrm{R} / 5 \text {-FOA } \\
\text { A/uridine }\end{array}$ & {$[66]$} \\
\hline QM6a_dtmus53_Dhax1_1 & QM6a_Dhax1_1 & hax1 disruption & R/amdS & This study \\
\hline QM6a_dtmus53_Dhax1_2 & QM6a_Dhax1_2 & haxl disruption & R/amdS & This study \\
\hline QM6a_dtmus53_Dhax1_3 & QM6a_Dhax1_3 & hax1 disruption & R/amdS & This study \\
\hline QM6a_dtmus53_Dhax1_8 & QM6a_Dhax1_8 & hax1 disruption & R/amdS & This study \\
\hline $\begin{array}{l}\text { QM6a__tmus53__pyr4_Pbg/1::hax1 QM6a } \\
\text { tion of pyr4 gene) }\end{array}$ & QM6a_OEhax1 QM6a & haxl overexpression & $\begin{array}{l}\text { R/5-FOA } \\
\text { A/uridine }\end{array}$ & This study \\
\hline 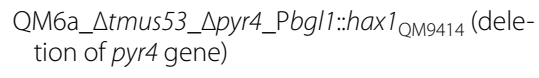 & QM6a_OEhax1 & haxl overexpression & $\begin{array}{l}\mathrm{R} / 5 \text {-FOA } \\
\text { A/uridine }\end{array}$ & This study \\
\hline $\begin{array}{l}\text { QM6a_ } \Delta t \text { tmus53_spyr4_Pbg/1::hax } 1_{\text {Rut-C30 }} \text { (dele- } \\
\text { tion of pyr4 gene) }\end{array}$ & QM6a_OEhax1 Rut-C30 $_{\text {-C }}$ & hax 1 overexpression & $\begin{array}{l}\text { R/5-FOA } \\
\text { A/uridine }\end{array}$ & This study \\
\hline QM9414 & & recipient strain & & ATCC 26921 \\
\hline QM9414_Dhax1_8 & & hax1 disruption & R/amdS & This study \\
\hline QM9414_Dhax1_10 & & haxl disruption & R/amdS & This study \\
\hline QM9414_Dhax1_14 & & hax1 disruption & R/amdS & This study \\
\hline $\begin{array}{l}\text { QM9414_Dhax1_8__ppyr4::Pbg/1-hax1 QM9414 } \\
\text { (deletion of pyr4 gene) }\end{array}$ & QM9414_Dhax1_14_OEhax1 QM9414 & haxl overexpression & $\begin{array}{l}\text { R/amdS } \\
\text { R/5-FOA } \\
\text { A/uridine }\end{array}$ & This study \\
\hline $\begin{array}{l}\text { QM9414_Dhax1_8__pyr4::Pbg/1-hax1 }{ }_{\text {Rut-C30 }} \\
\text { (deletion of pyr4 gene) }\end{array}$ & QM9414_Dhax1_14_OEhax1 ${ }_{\text {Rut-C30 }}$ & haxl overexpression & $\begin{array}{l}\text { R/amdS } \\
\text { R/5-FOA } \\
\text { A/uridine }\end{array}$ & This study \\
\hline Rut-C30 & & RACE & & ATCC 56765 \\
\hline
\end{tabular}

${ }^{a} \mathrm{R} /$, resistance; $\mathrm{A} /$, auxotrophy 
p5-A-3 contains the hax 15'- and 3'-flanks interrupted by the amdS marker gene in forward orientation.

For generation of the haxl overexpression constructs pCD- $\Delta$ pyr4-Pbgl1-hax $1_{\mathrm{QM6a}}$, pCD- $\Delta$ pyr4-Pbgl1hax $1_{\mathrm{QM} 9414}$ and $\mathrm{pCD}-\Delta$ pyr4-Pbgl1-hax $1_{\text {Rut-C30, the }}$ respective haxl versions were amplified using chromosomal DNA of T. reesei QM6a as template. The following primers were used: hax1 for_QM6a_BcuI and hax1 rev_3' $\mathrm{QM} 6 \mathrm{a}$ for the $262 \mathrm{bp} \operatorname{hax} 1_{\mathrm{QM6a}}$; hax1 for_QM9414 BcuI and hax1 rev_3'QM6a for the 299 bp hax1 ${ }_{\mathrm{QM} 9414}$ and hax1 for_Rut-C30_BcuI and hax1 rev_3'QM6a for the $428 \mathrm{bp} h a x 1_{\text {Rut-C30. }}$. The purified PCR products were blunt-end ligated into pJET1.2 (Thermo Scientific, Waltham, MA, USA) and the appropriate orientation was verified by digest with BcuI and XbaI. In a next step, a $997 \mathrm{bp}$ fragment of the bgl1 promoter was PCR-amplified using the primers Pbgl1 for_Kpn2I and Pbgl1 rev-NheI, then digested with Kpn2I and NheI, and subsequently cloned into the respective pJET-hax1 vectors digested with Kpn2I and BcuI. To prevent positioning of the hax1 gene and the foreign $5^{\prime}$-untranslated region of bgl1 next to each other, the terminal point of the promoter fragment was chosen to be equal to the transcriptional start point previously defined for this gene [56]. For construction of the final haxl overexpression cassettes, the Pbgl1hax 1 fusion products were isolated from the plasmids by digestion with Kpn2I and XbaI, extracted from a gel, and introduced into BcuI/Kpn2I-digested pCD- $\Delta$ pyr4 (carrying the $c b h 2$ terminator [66]) in forward orientation.

For cloning of the constructs, Escherichia coli strain Top10 (Invitrogen, Life Technologies, Paisley, UK) was used. It was maintained on LB supplemented with $100 \mu \mathrm{g} /$ $\mathrm{ml}$ ampicillin or spectinomycin and grown at $37^{\circ} \mathrm{C}$. All PCRs were performed applying peqGOLD Pwo DNA polymerase (PEQLAB, Biotechnologie, Erlangen, Germany) according to the manufacturer's instructions. The primers used are listed in Table 2. Final constructs were verified by sequencing (Microsynth, Balgach, Switzerland).

\section{Fungal transformation}

Accidental disruption of hax1 (Dhax1) in QM9414 occurred by usage of $9 \mu \mathrm{g}$ of the vector pAMDS (a derivate of pUC19 containing the $3864 \mathrm{bp}$ amdS gene) in an optimized protocol for particle bombardment [67]. Selection for positive transformants carrying the amdS gene, was performed on minimal medium $\left(72.9 \mathrm{mM} \mathrm{KH}_{2} \mathrm{PO}_{4}\right.$, $10.2 \mathrm{mM}$ sodium citrate, $1 \%(\mathrm{w} / \mathrm{v}) \mathrm{D}$-glucose, $20 \mathrm{ml} / \mathrm{L}$ trace element solution (see MA medium [65]), and 1.5\% agar noble dissolved in ultrapure $\mathrm{H}_{2} \mathrm{O}$ ) containing acetamide. After autoclaving, acetamide, $\mathrm{CsCl}$ and $\mathrm{MgSO}_{4}$ were added from sterile-filtered stock solutions to final concentrations of 10,10 , and $24.3 \mathrm{mM}$, respectively.
Protoplast transformation of T. reesei was performed as described previously [68]. QM6a_Dhax1 strains resulted from transformation of $13 \mu \mathrm{g}$ hax $15^{\prime}$-amdS3' DNA derived from a HindIII/Acc65I-digest of p5-A-3 and extraction from a gel. The template DNA was resuspended in $15 \mu \mathrm{l}$ sterile $\mathrm{dH}_{2} \mathrm{O}$ and used for transformation of $10^{7}$ protoplasts (in $150 \mu \mathrm{l}$ ) of QM6a_dtmus53. $100 \mu \mathrm{l}-2 \mathrm{ml}$ of the transformation reaction were added to $20 \mathrm{ml}$ melted, $50{ }^{\circ} \mathrm{C}$ warm amdS selection medium supplemented with $1.2 \mathrm{M}$ sorbitol. This mixture was poured into sterile petri dishes.

For overexpression of hax1 (OEhax1), $200 \mu \mathrm{g}$ of the NotI-digested construct pCD- $\Delta$ pyr4-Pbgl1hax $1_{\mathrm{QM} 6 a}, \quad \mathrm{pCD}-\Delta$ pyr4-Pbgl1-hax $1_{\mathrm{QM} 9414,}$ or $\mathrm{pCD}$ $\Delta$ pyr4-Pbgl1-hax $1_{\text {Rut-C30 }}$ were used for transformation of $10^{7}$ protoplasts (in $150 \mu \mathrm{l}$ ) of QM9414_Dhax1 or QM6a_dtmus53. Selection for pyr4 deleted transformants was performed on MEX agar containing $1.2 \mathrm{M}$ sorbitol, $1.5 \mathrm{mg} / \mathrm{ml} 5$-FOA, and $5 \mathrm{mM}$ uridine as described by Derntl and co-workers [66].

Plates were incubated at $30^{\circ} \mathrm{C}$ for $3-7$ days until colonies were visible.

\section{Genotypic characterization}

For an initial identification of uridine auxotroph OEhax1 strains, candidates were grown on MA medium containing $1 \%$ glycerol as a carbon source without peptone or uridine. The OEhaxl candidates that were unable to grow under these conditions were tested by PCR using the primers 5pyr4_fwd(BglII) and hax1 rev_3'QM6a.

For Dhax1 strains, homokaryotic strains were generated by three rounds of vegetative spore propagation on selection medium. In case of QM9414_Dhax1 strains, the locus of integration was identified via inverse PCR and verified by Southern blot analysis. In case of QM6a Dhax 1 strains correct integration of the construct was tested by PCR and by sequencing.

Extraction of chromosomal DNA for candidate screening and Southern blot analysis was performed as described previously $[65,66]$. For Southern blot analysis, the chromosomal DNA of QM9414_Dhax1 strains was digested with SacII, resulting in a 2960 bp fragment specific for the wild type and a 5178 bp fragment specific for disruption of hax1. The locus-specific biotinylated probe applied for hybridization was derived from a PCR using the primer pair locus for and locus rev and the Long-PCR Enzyme Mix (Thermo Scientific) for amplification.

PCR analysis for screening for Dhaxl candidates was performed using the same polymerase and primers. For verification of OEhax1 transformants via PCR, GoTaq G2 polymerase (Promega) was applied. DNA sequencing was 
Table 2 Primers and probes used in this study

\begin{tabular}{|c|c|c|}
\hline Name & Sequence $\left(5^{\prime}-3^{\prime}\right)$ & Employment(s) \\
\hline act1f & TGAGAGCGGTGGTATCCACG & $\mathrm{qPCR}$ \\
\hline act1r & GGTACCACCAGACATGACAATGTTG & qPCR \\
\hline amdS inv for & CAAAGGAAGAATCCCTTCAGGGTTGCGTTTCCAG & Inverse PCR \\
\hline amdS inv rev & CGCAGTTGCGTGGGATGACATTCATACTCAAGAC & Inverse PCR \\
\hline hax1 for_down-Intron & CCAGCTCCAACAGAACCAGG & Sequencing \\
\hline hax for_inter-Intron & GCAATGTCGCCAGGCACCG & $\mathrm{qPCR}$ \\
\hline hax1 for_qPCR_QM9414 & GTTCAAGCCCGTTCAAGCCC & $\mathrm{qPCR}$ \\
\hline hax1 for_QM6a_Bcul & CAGCAGTACTAGTCCCACCGGCAGGTGGCTAAACGG & Qualitative PCR, cloning OEhax \\
\hline hax1 for_QM9414_Bcul & CAGCAGACTAGTGGTCAGGCCCGTTCAAGCCCGTTC & Qualitative PCR, cloning OEhax \\
\hline hax1 for_Rut-C30_Bcul & CAAGACTAGTGAAGTTCCACACGGATACAGAGACACAACATG & Qualitative PCR, cloning OEhax \\
\hline hax1 for_3 & TGCCTTGCATCGTACCGCTG & $q P C R$ \\
\hline hax1 for_3'RACE_3 & AGGTGCTAAAACTGAATGGATGG & RACE \\
\hline hax1 rev & TCCGCAAAACGAACCGAACC & qPCR \\
\hline hax1 rev_down-Intron & GAGCGGCAGGAGGATGGATTC & qPCR \\
\hline hax1 rev_inter-Intron & GAGGTGCGCCGCGAATCTG & Sequencing \\
\hline hax1 rev kurz & TGAGTCGAGGGGCTACTGCAAGTAC & qPCR \\
\hline hax1 rev_up-Intron & GCCATCCATTCAGTTTTAGCACC & qPCR, RACE \\
\hline hax1 rev_1.Intron & CACGCATTTCATCTGGCCATTG & $\mathrm{qPCR}$ \\
\hline hax1 rev_3'QM6a & CACGCATTTCATCTGGCCATTGAGTATCTACG & Qualitative PCR, cloning OEhax \\
\hline hax1 rev_3-39_Xbal & CAGCAGTCTAGAGACTTCTTGGTATTGTCGTCACCTTATG & Sequencing \\
\hline hax1 rev_5'RACE_2 & CTACGATACACCGACTTCTTGG & RACE \\
\hline hax1 rev_5'RACE_4 & CGTCCCCACAATAGCCATGAGCCG & RACE \\
\hline Isopropylmalate synthase forward & TCCCGAATGCTTCTCCGACA & qPCR \\
\hline Isopropylmalatesynthase_rev & GCTCTCTCTGTCTCCGATGTTGG & $\mathrm{qPCR}$ \\
\hline Locus for & CGCGCTCTCTTTTCCTCCTT & Dhax1 candidate screening \\
\hline Locus rev & GCAGAACCCAGGACACAAAGAGC & Dhax1 candidate screening \\
\hline Locus 3'for Acc65I & GGTACCTGAGGTGTATGATTCCGTGATG & Cloning Dhax1 \\
\hline Locus 3'rev Xbal & TCTAGATCCTGTTCGGCCCAGCCC & Cloning Dhax1 \\
\hline Locus 5'for Sall & GGGAATAACCAATGCCTCTGAAGCTT & Cloning Dhax1 \\
\hline Locus 5'rev Hindlll & GGGAATAACCAATGCCTCTGAAGCTT & Cloning Dhax1 \\
\hline Pbgl1 for_Kpn2l & CAAGTCCGGAGCAAGCGATAACCATAGGTA & Cloning OEhax1 \\
\hline Pbgl1 rev-Nhel & CAACAAGCTAGCCTCAACAAAGCAGAGTCTTG & Cloning OEhax1 \\
\hline 5pyr4_fwd(Bglll) & GCGGAAGATCTCGAGATAGTATCTC & OEhax1 candidate screening \\
\hline sar1fw & TGGATCGTCAACTGGTTCTACGA & qPCR \\
\hline sar1rev & GCATGTGTAGCAACGTGGTCTTT & qPCR \\
\hline sonde hax_5-biotin & [biotin]CGTCAGCCACCAGCCACCGTTTAGCCACCT & HAX1 enrichment \\
\hline Unknown protein forward & CGCCGTATTGGGGTTCATTG & qPCR \\
\hline Unknown protein reverse & GGCTAAACGTTGTCTCGGAG & qPCR \\
\hline up-hax1 for_1 & ACATGCAGGAGATTGGGCGTC & $q P C R$ \\
\hline up-hax1 for_2 & CGCGGCTTAATCAGAGGTGGG & $\mathrm{qPCR}$ \\
\hline
\end{tabular}

performed at Microsynth. All primers used for candidate screening are listed in Table 2.

\section{Inverse PCR}

For the identification of the locus that was targeted by integration of the amdS marker in QM9414_Dhax1 strains, an inverse PCR was performed as follows. $20 \mu \mathrm{g}$ of chromosomal DNA were digested with either Acc65I or NotI (Thermo Scientific) at a final concentration of 1 $\mathrm{U} / \mu \mathrm{l}$ in a total reaction volume of $20 \mu \mathrm{l}$ according to the manufacturer's instructions. After heat inactivation, $2 \mu \mathrm{l}$ of T4 Ligase (Promega, 1-3 U/ $\mu \mathrm{l}$ ) and the corresponding buffer were added and ligation was performed at $18{ }^{\circ} \mathrm{C}$ for $90 \mathrm{~min}$. Subsequently, the ligation was stopped by heat inactivation and $1 \mu \mathrm{l}$ was applied as template in a $25 \mu \mathrm{l}$ inverse PCR reaction, initially using the primers 
amdS inv for and amdS inv rev. For further approaches, the primers locus for and locus rev annealing to the identified regions were applied. All amplifications were performed in an iCycler (Bio-Rad, Hercules, CA, USA) using the Long-PCR Enzyme Mix (Thermo Scientific) and the following program: initial denaturation at $94{ }^{\circ} \mathrm{C}$ for $3 \mathrm{~min}$, followed by 30 cycles of $30 \mathrm{~s}$ at $94{ }^{\circ} \mathrm{C}, 30 \mathrm{~s}$ at $59{ }^{\circ} \mathrm{C}$ and $3 \mathrm{~min}$ at $72{ }^{\circ} \mathrm{C}$, and final elongation at $72{ }^{\circ} \mathrm{C}$ for $5 \mathrm{~min}$. The DNA fragments were sequenced by MWG Biotech (Ebersberg, Germany).

\section{RNA stability assay}

The strains QM6a, QM9414, and Rut-C30 were cultivated in $25 \mathrm{ml}$ MA medium containing $1 \%(\mathrm{w} / \mathrm{v}) \alpha-\mathrm{D}-$ lactose and $10^{9}$ conidia per litre (final concentration) at $30{ }^{\circ} \mathrm{C}$ and $180 \mathrm{rpm}$ for $24 \mathrm{~h}$. The cultivation was carried out in biological triplicates. Then, the transcription was stopped by addition of $16 \mu \mathrm{g} / \mathrm{ml}$ (final concentration) of the inhibitor DRB. The cultures were further incubated and after 30,60, 90, and $120 \mathrm{~min}, 500 \mu \mathrm{l}$ samples were taken. A reference sample was taken from each culture before addition of DRB. The three biological replicates of each strain were pooled to one $1.5 \mathrm{ml}$ sample. Mycelia were harvested by centrifugation and frozen in liquid nitrogen. Finally, the RNA was extracted, cDNA synthesis was performed and the samples were analysed via quantitative PCR as described in "Transcript analysis" section.

\section{Transcript analysis}

Extraction of RNA from fungal mycelia, cDNA synthesis, and quantitative PCRs were performed as described previously [69]. Template cDNAs were diluted 1:100 (QM9414) or 1:20 (QM6a). Analysis was carried out in triplicates. The following PCR protocols were run: $3 \mathrm{~min}$ initial denaturation at $95^{\circ} \mathrm{C}$, followed by 50 cycles of $15 \mathrm{~s}$ at $95{ }^{\circ} \mathrm{C}, 15 \mathrm{~s}$ at $60{ }^{\circ} \mathrm{C}$ and $20 \mathrm{~s}$ at $72{ }^{\circ} \mathrm{C}$ (for hax 1 and act) or $3 \mathrm{~min}$ initial denaturation at $95^{\circ} \mathrm{C}$, followed by 40 cycles of $15 \mathrm{~s}$ at $95{ }^{\circ} \mathrm{C}$ and $120 \mathrm{~s}$ at $64{ }^{\circ} \mathrm{C}$ (for sar1). Control reactions, data normalization using sarl and act as reference genes and calculations were performed as published previously [70].

Qualitative PCRs for estimating the abundance of hax$1_{\mathrm{QM} 62}, h a x 1_{\mathrm{QM} 9414,}$ and $h a x 1_{\mathrm{Rut}-\mathrm{C} 30}$ were performed using the Q5 High-Fidelity DNA Polymerase (New England Biolabs, Ipswich, MA, USA) according to the manufacturer's instructions. The template cDNAs were diluted 1:20. Amplification was performed running the following program: initial denaturation at $98^{\circ} \mathrm{C}$ for $30 \mathrm{~s}$, followed by 35 cycles of $10 \mathrm{~s}$ at $98{ }^{\circ} \mathrm{C}, 10 \mathrm{~s}$ at $70{ }^{\circ} \mathrm{C}$ and $20 \mathrm{~s}$ at $72{ }^{\circ} \mathrm{C}$, and final elongation at $72{ }^{\circ} \mathrm{C}$ for $2 \mathrm{~min}$. The resulting fragments $(262,299$, and $428 \mathrm{bp})$ were analysed on a $1.5 \%$ agarose gel applying a GeneRuler 50 bp DNA
Ladder (Thermo Scientific) for size estimation. Primer sequences for all transcript analyses are provided in Table 2.

\section{RACE and enrichment of HAX1}

$5^{\prime}$ and $3^{\prime}$ RACE was performed using the $5^{\prime} / 3^{\prime}$ RACE Kit, 2nd generation (Roche, Basel, Switzerland). For PCRs, the GoTaq G2 polymerase (Promega) was applied. Primer sequences for RACE are provided in Table 2.

$5^{\prime}$ RACE was carried out according to manufacturer's instructions, applying $0.9-1 \mu \mathrm{g}$ of DNase I digested RNA extracts for cDNA synthesis in a total reaction volume of $20 \mu \mathrm{l}$. For this initial reverse transcription step, the gene specific primer hax1 rev_1.Intron was used. After RNase A digestion and purification with the QIAquick PCR Purification Kit (Qiagen, Hilden, Germany) based on the modified protocol for RACE applications recommended by Roche, a poly(A)-tailing was performed. Subsequently, the hax 1 fragments were specifically amplified from the total pool with the Oligo dT-Anchor Primer (included in the kit) and hax1 rev_5'RACE_2 in a first PCR. The resulting product was diluted 1:50 and used as a template for a nested PCR with either hax1 rev_up-Intron or hax1 rev_5'RACE_4 and the PCR Anchor primer included in the kit.

For $3^{\prime}$ RACE, classical analysis was performed according to manufacturer's instructions, applying $0.45 \mu \mathrm{g}$ of DNase I digested RNA from $T$. reesei QM9414 in a total reaction volume of $20 \mu \mathrm{l}$. After reverse transcription with the Oligo dT-Anchor Primer, cDNAs were RNase A digested and used for amplification of hax1 applying the gene specific primers up hax 1 for_2 and hax1 for_3'RACE_3 for the initial and nested PCRs, respectively. Further $3^{\prime}$ RACE approaches based on prior enrichment of $H A X 1$ were performed. For this purpose, HAX1 was enriched from 1.25 to $2.1 \mathrm{mg}$ total RNA extract using a biotinylated and HPLC-purified hax1 specific DNA probe (sonde hax_5-Biotin) as well as streptavidin-linked magnetic beads included in the $\mu M_{A C S}{ }^{\mathrm{TM}}$ Streptavidin Kit and the corresponding $\mu$ MACS separator (Miltenyi Biotec, Bergisch Gladbach, Germany) based on manufacturer's instructions. According to the unusual high calculated melting temperature of the biotinylated probe, initial denaturation was performed at $85{ }^{\circ} \mathrm{C}$ for $5 \mathrm{~min}$ and annealing to appropriate amounts of streptavidin-linked magnetic beads was done at $70{ }^{\circ} \mathrm{C}$ for $15 \mathrm{~min}$. RNase-free TEN buffer (10 mM Tris/ $\mathrm{HCl}, \mathrm{pH} 8.0 ; 1 \mathrm{mM}$ EDTA; $100 \mathrm{mM} \mathrm{NaCl}$ ) and TE buffer $(10 \mathrm{mM}$ Tris/HCl, pH 8.0; 1 mM EDTA) were used for binding and washing, respectively. Enriched RNA was eluted with $150 \mu \mathrm{l}$ RNase-free $\mathrm{dH}_{2} \mathrm{O}$ and digested with DNase I (Thermo Scientific). For poly(A)-tailing followed by RACE analysis, the enriched RNA was precipitated with isopropanol, 
washed with $70 \%(\mathrm{w} / \mathrm{v})$ ethanol and dissolved in $20 \mu \mathrm{l}$ RNase-free $\mathrm{dH}_{2} \mathrm{O}$. Poly(A)-tailing was performed using $19 \mu \mathrm{l}$ of the resulting RNA in a total reaction volume of $25 \mu \mathrm{l}$. For proceeding to cDNA synthesis without prior poly(A)-tailing, the RNA was purified using the GeneJET RNA Cleanup and Concentration Micro Kit (Thermo Scientific) as instructed in the protocol for purification of DNase I digested samples. In this case, the RNA was eluted from four columns with $10 \mu \mathrm{l}$ each and pooled for cDNA synthesis. Reverse transcription and further $3^{\prime}$ RACE analysis steps were performed as described before using the RACE Kit and applying the gene specific primers up hax 1 for_ 2 and hax 1 for_3'RACE_3 for the initial and nested PCRs, respectively.

For both, $3^{\prime}$ and $5^{\prime}$ RACE, the final PCR products were extracted from a gel, blunt-end ligated into pJET1.2 (Thermo Scientific) and analysed by sequencing (Microsynth).

\section{Enzyme assays}

The $\beta$-glucosidase activity was assayed in $50 \mathrm{mM}$ sodium citrate buffer at $\mathrm{pH} 5.0$ using $p$-nitrophenyl- $\beta$ $\mathrm{D}$-glucopyranoside as a substrate. The enzyme assay was performed at $50{ }^{\circ} \mathrm{C}$ for $30 \mathrm{~min}$ as previously described [71] and the activity was calculated from the absorbance at $405 \mathrm{~nm}$ based on the Lambert-Beer law.

The cellulase activity was assayed in $25 \mathrm{mM}$ sodium acetate buffer $\mathrm{pH} 4.5$ using Azo-Cellazyme $\mathrm{C}$ tablets (Megazyme, Wicklow, Ireland) as substrate, essentially according to the manufacturer's instructions. The reaction time was increased to $30 \mathrm{~min}-5 \mathrm{~h}$ until detectable values were obtained. The same reaction times were used for all strains cultivated for the same time period within one experiment, and samples with higher cellulase activity were adjusted by dilution to enable comparison. Cellulase activities given in $\mu$ were calculated from the absorbance at $590 \mathrm{~nm}$ for $10 \mathrm{~min}$ reaction time based on the equation $\mu=232.6 *$ Abs +5 [72].

One unit is defined as the amount of enzyme required to release $1 \mu \mathrm{mol}$ of $\mathrm{D}$-glucose reducing-sugar-equivalents per minute under the respective assay conditions. For the final timepoints of cultivation, the enzymatic activities were referred to the biomass dry weight derived from incubation of the harvested mycelia at $80^{\circ} \mathrm{C}$ for $24 \mathrm{~h}$.

\section{Structure and sequence analysis tools}

Genome analysis and BLAST were performed using the NCBI database [54] and the sequence of Trichoderma reesei QM6a v2.0 accessible in the JGI database [51]. For structural gene prediction, the web server AUGUSTUS described by Stank and Morgenstern was used [52]. Codon usage was calculated applying the online Codon Usage Calculator of Biologics Corp
[53]. In silico prediction of RNA secondary structures of minimized free energy was performed using the RNAfold Web server [55] included in the ViennaRNA Package 2.0 [73], provided by the University of Vienna. Displayed structures are based on HAX1 sequences without polyA-tail; however, the addition of a random polyA-tail did not change structures.

\section{Statistical test}

For statistical analyses of the data, the program GraphPad Prism 5.00.288 was used to perform ANOVA $(P<0.05)$ tests and Tukey's multiple comparison test as posttest.

\section{Additional files}

Additional file 1. Transcript levels of the neighbouring genes of the targeted site for amdS integration. RT-qPCR results of an undescribed protein referred to as hypothetical protein (Protein ID 108999) (A) and the 2-isopropylmalate synthase (Protein ID 79495) (B) in T. reesei strains QM9414 (PS; black bars), QM9414_Dhax1_8 (D8; orange bars) and QM9414_Dhax1_10 (D10; red bars). cDNAs used as templates were derived from cultures that were pre-grown and transferred to medium without carbon source, $1 \%(\mathrm{~W} / \mathrm{V})$ D-glucose $(\mathrm{G})$ or $1.5 \mathrm{mM}$ sophorose $(\mathrm{S})$ for $3 \mathrm{~h}$. Transcript levels were normalized to act and sarl, refer to QM9414 (no carbon source) and are given in logarithmic scale (lg). Analysis was performed in technical triplicates. The error bars depict the standard deviation and different letters denote statistical difference among compared data employing ANOVA $(P<0.05)$.

Additional file 2. Codon usage of the predicted hax 1 gene. For each of the 64 codons potentially making up a protein the following information is listed: base triplet; the encoded amino acid (given as one-letter code); fraction out of the 313 codons constituting hax 1 ; frequency per thousand; absolute number of occurrence (from a total of 313 codons). Asterisks indicate stop codons.

Additional file 3. Curves of RT-qPCR for the detection of the hax 1 transcript in T. reesei QM6a. T. reesei QM6a was cultivated on 1\% D-glucose (brown) or without carbon source (blue). The qPCR was performed with primer pair up-hax 1 for_2 and hax1 rev 1.Intron (compare Fig. 2C, PCR 2). Analysis was performed in technical triplicates. A no template control (red) and a negative control (yellow) were included in the run. Measured fluorescence is plotted against the number PCR cycles.

Additional file 4. Alignment of the hax 1 locus of the investigated T. reesei strains. The hax 1 locus (letters without background) and the adjacent regions encoding the neighbouring genes (letters on grey background) of different T. reesei strains were PCR-amplified from chromosomal DNA using the primers locus for and locus rev and sequenced using the primers hax1 rev_inter-Intron, hax1 rev_3-39_Xbal, up-hax1 for_2 and hax1 for_down-Intron. Assembled sequences determined for Rut-C30 (purple letters) and QM9414 (green letters) were aligned to the genome of T. reesei QM6a (black, bold, underlined letters) accessible in the Joint Genome Institute database. The whole investigated sequence revealed 100\% identity.

Additional file 5. RNA stability of the three HAX1 versions. The T. reesei strains QM6a (blue), QM9414 (yellow) and Rut-C30 (purple) were grown in MA medium containing $1 \%(\mathrm{~W} / \mathrm{V})$ a-D-lactose for $24 \mathrm{~h}$ and transcription was inhibited by the addition of DRB. Samples were taken before the addition of DRB (reference sample) and $30 \mathrm{~min}, 60 \mathrm{~min}, 90 \mathrm{~min}$ and $120 \mathrm{~min}$ after the addition of DRB. RT-qPCR was performed using CDNA from

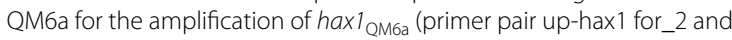
hax1 rev_1.Intron, blue), from QM9414 for the amplification of hax ${ }_{\mathrm{QM} 9414}$ (primer pair hax1 for_qPCR_QM9414 and hax1 rev_up-Intron; yellow) 
and from Rut-C30 for the amplification of hax Rut-C30 $_{\text {(primer pair up-hax }}$ for_1 and hax 1 rev_up-Intron, purple). Transcript levels were normalized to act and sar1, refer to the sample taken before the addition of DRB (time point $0 \mathrm{~min}$ ) and are given in logarithmic scale (lg). All standard deviations of technical triplicates are $<0.06$.

Additional file 6. RT-qPCR of the three hax 1 versions in QM9414 disruption strains. Analysis of the formation of hax 1 transcripts, i.e., hax $1_{\text {QM6a }}$ (graph on top), hax $1_{\mathrm{QM} 9414}$ (graph in the middle) and hax $1_{\text {Rut-C30 }}$ (graph at the bottom), in QM9414_Dhax1_8 (green) and QM9414_Dhax1_14 (blue) and their parent strain QM9414 as a positive control (grey). The cDNAs used as templates were derived from cultivation on lactose for $48 \mathrm{~h}$ (QM9414_Dhax1 strains) or replacement to medium without carbon source (positive control). For amplification the primer pairs up-hax 1 for_2 and hax1 rev_1.Intron (hax1 ${ }_{\text {om6 }}$ ), hax1 for_qPCR_QM9414 and hax1 rev_up-Intron (hax1 QM9414 $_{\text {) }}$, or up-hax 1 for_1 and hax1 rev_up-Intron ( hax $1_{\text {Rut-C30 }}$ ) were used. Analysis was performed in technical triplicates. A no template control (red) and a negative control (yellow) were included in each run. Measured fluorescence is plotted against the number PCR cycles.

\section{Authors' contributions}

MP generated the QM9414 hax1 disruption strains, carried out $\beta$-glucosidase assays and identified the locus targeted by amdS integration via inverse PCR. PT carried out cellulase assays, transcript analyses, RACE and structural analyses, constructed QM6a hax1 disruption- and all hax1 overexpression strains, and drafted the manuscript. RLM participated in conception of the study. ARMA participated in conception of the study, supervised the experiments and accurately revised the manuscript. All authors read and approved the final manuscript.

\section{Author details}

${ }^{1}$ Christian Doppler Laboratory for Optimized Expression of Carbohydrate-active Enzymes, Institute of Chemical, Environmental and Bioscience Engineering, TU Wien, Gumpendorfer Str. 1a, 1060 Vienna, Austria. ${ }^{2}$ Institute of Chemical, Environmental and Bioscience Engineering, TU Wien, Gumpendorfer Str. 1a, 1060 Vienna, Austria.

\section{Competing interests}

Novozymes has filed a patent related to the content of our study.

\section{Availability of data and materials}

All data generated or analysed during this study are included in this published article and additional information files.

\section{Consent for publication}

Not applicable.

\section{Ethics approval and consent to participate}

Not applicable.

\section{Funding}

This work was supported by a grant from the Austrian Science Fund (FWF): [P26618]. Further financial support by Novozymes, by the Austrian Federal Ministry of Science, Research and Economy and the National Foundation for Research, Technology and Development is gratefully acknowledged.

\section{Publisher's Note}

Springer Nature remains neutral with regard to jurisdictional claims in published maps and institutional affiliations.

Received: 1 September 2017 Accepted: 14 March 2018

Published online: 23 March 2018

\section{References}

1. Kuhls K, Lieckfeldt E, Samuels GJ, Kovacs W, Meyer W, Petrini O, et al. Molecular evidence that the asexual industrial fungus Trichoderma reesei is a clonal derivative of the ascomycete Hypocrea jecorina. Proc Natl Acad Sci USA. 1996;93:7755-60.

2. Ouyang J, Yan M, Kong D, Xu L. A complete protein pattern of cellulase and hemicellulase genes in the filamentous fungus Trichoderma reesei. Biotechnol J. 2006;1:1266-74.

3. Teeri T, Salovouri I, Knowles J. The molecular cloning of the major cellulase gene from Trichoderma reesei. Biotechnology. 1983;1:696-9.

4. Törrönen A, Harkki A, Rouvinen J. Three-dimensional structure of endo1,4-beta-xylanase II from Trichoderma reesei: two conformational states in the active site. EMBO J. 1994;13:2493-501.

5. Galante YM, De Conti A, Monteverdi R. Application of Trichoderma enzymes in the food and feed industries. In: Harman GE, Kubicek CP, editors. Trichoderma and Gliocladium. London: Taylor \& Francis; 1998. p. 327-42.

6. Galante YM, De Conti A, Monteverdi R. Application of Trichoderma enzymes in the textile industry. In: Harman GE, Kubicek CP, editors. Trichoderma and Gliocladium. London: Taylor \& Francis; 1998. p. 311-25.

7. Buchert J, Oksanen T, Pere J, Siika-aho M, Suurnäkki A, Viikari L. Applications of Trichoderma reesei enzymes in the pulp and paper industry. In: Harman GE, Kubicek CP, editors. Trichoderma and Gliocladium. London: Taylor \& Francis; 1998. p. 343-57.

8. Kumar R, Singh S, Singh OV. Bioconversion of lignocellulosic biomass: biochemical and molecular perspectives. J Ind Microbiol Biotechnol. 2008;35:377-91.

9. Ragauskas AJ, Williams CK, Davison BH, Britovsek G, Cairney J, Eckert CA, et al. The path forward for biofuels and biomaterials. Science. 2006;311:484-9.

10. Hahn-Hägerdal B, Galbe M, Gorwa-Grauslund MF, Liden G, Zacchi G. Bio-ethanol - the fuel of tomorrow from the residues of today. Trends Biotechnol. 2006;24:549-56.

11. Zhang X, Li Y, Zhao X, Bai F. Constitutive cellulase production from glucose using the recombinant Trichoderma reesei strain overexpressing an artificial transcription activator. Bioresour Technol. 2017;223:317-22.

12. Peterson R, Nevalainen H. Trichoderma reesei RUT-C30 - 30 years of strain improvement. Microbiology. 2012;158:58-68.

13. Zhang F, Bai F, Zhao X. Enhanced cellulase production from Trichoderma reesei Rut-C30 by engineering with an artificial zinc finger protein library. Biotechnol J. 2016;11:1282-90.

14. Kubicek CP, Mikus M, Schuster A, Schmoll M, Seiboth B. Metabolic engineering strategies for the improvement of cellulase production by Hypocrea jecorina. Biotechnol Biofuels. 2009;2:19.

15. Bischof RH, Ramoni J, Seiboth B. Cellulases and beyond: the first 70 years of the enzyme producer Trichoderma reesei. Microb Cell Fact. 2016;15:106

16. Mandels M, Reese ET. Induction of cellulase in Trichoderma viride as influenced by carbon sources and metals. J Bacteriol. 1957;73:269-78.

17. el-Gogary S, Leite A, Crivellaro O, Eveleigh DE, el-Dorry H. Mechanism by which cellulose triggers cellobiohydrolase I gene expression in Trichoderma reesei. Proc Natl Acad Sci USA. 1989;86:6138-41.

18. Mach RL, Strauss J, Zeilinger S, Schindler M, Kubicek CP. Carbon catabolite repression of xylanase I (xyn 1) gene expression in Trichoderma reesei. Mol Microbiol. 1996;21:1273-81.

19. Montenecourt BS, Eveleigh DE. Preparation of mutants of Trichoderma reesei with enhanced cellulase production. Appl Environ Microbiol. 1977;34:777-82.

20. Montenecourt BS, Eveleigh DE. Semiquantitative plate assay for determination of cellulase production by Trichoderma viride. Appl Environ Microbiol. 1977;33:178-83.

21. Montenecourt BS, Eveleigh DE. Selective screening methods for the isolation of high yielding cellulase mutants of Trichoderma reesei. In: Brown RD, Jurasek L, editors. Hydrolysis of cellulose: mechanisms of enzymatic and acid catalysis. Washington, DC: American Chemical Society; 1979. p. 289-301.

22. Ilmén M, Thrane C, Penttilä M. The glucose repressor gene crel of Trichoderma: isolation and expression of a full-length and a truncated mutant form. Mol Gen Genet. 1996;251:451-60. 
23. Stricker AR, Grosstessner-Hain K, Würleitner E, Mach RL. Xyr1 (xylanase regulator 1) regulates both the hydrolytic enzyme system and D-xylose metabolism in Hypocrea jecorina. Eukaryot Cell. 2006;5:2128-37.

24. Stricker AR, Steiger MG, Mach RL. Xyr 1 receives the lactose induction signal and regulates lactose metabolism in Hypocrea jecorina. FEBS Lett. 2007:581:3915-20.

25. Aro N, Ilmén M, Saloheimo A, Penttilä M. ACEl of Trichoderma reesei is a repressor of cellulase and xylanase expression. Appl Environ Microbiol. 2003:69:56-65.

26. Aro N, Saloheimo A, Ilmén M, Penttilä M. ACEll, a novel transcriptional activator involved in regulation of cellulase and xylanase genes of Trichoderma reesei. J Biol Chem. 2001;276:24309-14.

27. Häkkinen M, Valkonen MJ, Westerholm-Parvinen A, Aro N, Arvas M, Vitikainen $M$, et al. Screening of candidate regulators for cellulase and hemicellulase production in Trichoderma reesei and identification of a factor essential for cellulase production. Biotechnol Biofuels. 2014;7:14

28. Denton JA, Kelly JM. Disruption of Trichoderma reesei cre2, encoding an ubiquitin C-terminal hydrolase, results in increased cellulase activity. BMC Biotechnol. 2011;11:103.

29. He R, Ma L, Li C, Jia W, Li D, Zhang D, et al. Trpac1, a pH response transcription regulator, is involved in cellulase gene expression in Trichoderma reesei. Enzyme Microb Technol. 2014;67:17-26.

30. Nitta M, Furukawa T, Shida Y, Mori K, Kuhara S, Morikawa Y, et al. A new Zn(II)(2)Cys(6)-type transcription factor BgIR regulates beta-glucosidase expression in Trichoderma reesei. Fungal Genet Biol. 2012;49:388-97.

31. Mattick JS, Makunin IV. Non-coding RNA. Hum Mol Genet. 2006;15(Spec No 1):R17-29.

32. Ponting CP, Oliver PL, Reik W. Evolution and functions of long noncoding RNAs. Cell. 2009:136:629-41.

33. Kapranov P, Cheng J, Dike S, Nix DA, Duttagupta R, Willingham AT, et al. RNA maps reveal new RNA classes and a possible function for pervasive transcription. Science. 2007;316:1484-8.

34. Djebali S, Davis CA, Merkel A, Dobin A, Lassmann T, Mortazavi A, et al. Landscape of transcription in human cells. Nature. 2012;489:101-8.

35. The ENCODE Project Consortium. Identification and analysis of functional elements in $1 \%$ of the human genome by the ENCODE pilot project. Nature. 2007:447:799-816.

36. Böhmdorfer $\mathrm{G}$, Wierzbicki AT. Control of chromatin structure by long noncoding RNA. Trends Cell Biol. 2015;25:623-32.

37. Roberts TC, Morris KV, Weinberg MS. Perspectives on the mechanism of transcriptional regulation by long non-coding RNAs. Epigenetics. 2014;9:13-20.

38. Dinger ME, Pang KC, Mercer TR, Mattick JS. Differentiating protein-coding and noncoding RNA: challenges and ambiguities. PLoS Comput Biol. 2008;4:e1000176.

39. Derrien T, Johnson R, Bussotti G, Tanzer A, Djebali S, Tilgner H, et al. The GENCODE v7 catalog of human long noncoding RNAs: analysis of their gene structure, evolution, and expression. Genome Res. 2012;22:1775-89.

40. Ariel F, Jegu T, Latrasse D, Romero-Barrios N, Christ A, Benhamed M, et al Noncoding transcription by alternative RNA polymerases dynamically regulates an auxin-driven chromatin loop. Mol Cell. 2014:55:383-96.

41. Ilik I, Akhtar A. roX RNAs Non-coding regulators of the male X chromosome in flies. RNA Biol. 2009:6:113-21.

42. Amrein H, Axel R. Genes expressed in neurons of adult male Drosophila. Cell. 1997:88:459-69.

43. Zhang J, Houston DW, King ML, Payne C, Wylie C, Heasman J. The role of maternal VegT in establishing the primary germ layers in Xenopus embryos. Cell. 1998;94:515-24.

44. Rinn JL, Kertesz M, Wang JK, Squazzo SL, Xu X, Brugmann SA, et al. Functional demarcation of active and silent chromatin domains in human HOX loci by noncoding RNAs. Cell. 2007;129:1311-23.

45. Brown CJ, Hendrich BD, Rupert JL, Lafreniere RG, Xing Y, Lawrence J, et al. The human XIST gene: analysis of a $17 \mathrm{~kb}$ inactive X-specific RNA that contains conserved repeats and is highly localized within the nucleus. Cell. 1992;71:527-42.

46. Martens JA, Laprade L, Winston F. Intergenic transcription is required to repress the Saccharomyces cerevisiae SER3 gene. Nature. 2004;429:571-4

47. Hirota K, Miyoshi T, Kugou K, Hoffman CS, Shibata T, Ohta K. Stepwise chromatin remodelling by a cascade of transcription initiation of noncoding RNAs. Nature. 2008;456:130-4.
48. Venter JC, Adams MD, Myers EW, Li PW, Mural RJ, Sutton GG, et al. The sequence of the human genome. Science. 2001;291:1304-51.

49. Nagalakshmi U, Wang Z, Waern K, Shou C, Raha D, Gerstein M, et al. The transcriptional landscape of the yeast genome defined by RNA sequencing. Science. 2008:320:1344-9.

50. Penttilä M, Nevalainen H, Ratto M, Salminen E, Knowles J. A versatile transformation system for the cellulolytic filamentous fungus Trichoderma reesei. Gene. 1987;61:155-64.

51. Joint Genome Institute (JGI): Trichoderma reesei v2.0. 2017. http://genom e.jgi-psf.org/Trire2/Trire2.home.html. Accessed 16 July 2017.

52. Stanke M, Morgenstern B. AUGUSTUS: a web server for gene prediction in eukaryotes that allows user-defined constraints. Nucleic Acids Res. 2005;33:W465-7

53. Codon Usage Calculator-Biologics Corp. http://www.biologicscorp. com/tools/CodonUsageCalculator. Accessed 10 Dec 2016.

54. National Center for Biotechnology Information (NCBI) database. 2017. https://www.ncbi.nlm.nhi.gov. Accessed 16 July 2017.

55. Gruber AR, Lorenz R, Bernhart SH, Neuböck R, Hofacker IL. The Vienna RNA websuite. Nucleic Acids Res. 2008;36:70-4.

56. Mach RL, Seiboth B, Myasnikov A, Gonzalez R, Strauss J, Harkki AM, et al. The bgll gene of Trichoderma reesei QM 9414 encodes an extracellular, cellulose-inducible beta-glucosidase involved in cellulase induction by sophorose. Mol Microbiol. 1995;16:687-97.

57. Glass NL, Schmoll M, Cate JH, Coradetti S. Plant cell wall deconstruction by ascomycete fungi. Annu Rev Microbiol. 2013;67:477-98.

58. Klaubauf S, Narang HM, Post H, Zhou M, Brunner K, Mach-Aigner AR, et al. Similar is not the same: differences in the function of the (hemi-) cellulolytic regulator XInR (XIr1/Xyr1) in filamentous fungi. Fungal Genet Biol. 2014:72:73-81.

59. Nehlin JO, Ronne H. Yeast MIG1 repressor is related to the mammalian early growth response and Wilms' tumour finger proteins. EMBO J. 1990;9:2891-8.

60. Pang KC, Frith MC, Mattick JS. Rapid evolution of noncoding RNAs: lack of conservation does not mean lack of function. Trends Genet. 2006;22:1-5.

61. Rinn JL, Chang HY. Genome regulation by long noncoding RNAs. Annu Rev Biochem. 2012:81:145-66.

62. Vance KW, Ponting CP. Transcriptional regulatory functions of nuclear long noncoding RNAs. Trends Genet. 2014;30:348-55.

63. Kohtz JD, Fishell G. Developmental regulation of EVF-1, a novel noncoding RNA transcribed upstream of the mouse Dlx6 gene. Gene Expr Patterns. 2004;4:407-12

64. Feng J, Bi C, Clark BS, Mady R, Shah P, Kohtz JD. The Evf-2 noncoding RNA is transcribed from the Dlx-5/6 ultraconserved region and functions as a Dlx-2 transcriptional coactivator. Genes Dev. 2006;20:1470-84.

65. Mandels M. Applications of cellulases. Biochem Soc Trans. 1985;13:414-6.

66. Derntl C, Kiesenhofer DP, Mach RL, Mach-Aigner AR. Novel strategies for genomic manipulation of Trichoderma reesei with the purpose of strain engineering. Appl Environ Microbiol. 2015;81:6314-23.

67. Hazell BW, Te'o VS, Bradner JR, Bergquist PL, Nevalainen KM. Rapid transformation of high cellulase-producing mutant strains of Trichoderma reesei by microprojectile bombardment. Lett Appl Microbiol. 2000;30:282-6.

68. Gruber F, Visser J, Kubicek CP, de Graaff LH. The development of a heterologous transformation system for the cellulolytic fungus Trichoderma reesei based on a pyrG-negative mutant strain. Curr Genet. 1990;18:71-6.

69. Mello-de-Sousa TM, Gorsche R, Rassinger A, Poças-Fonseca MJ, Mach RL, Mach-Aigner AR. A truncated form of the carbon catabolite repressor 1 increases cellulase production in Trichoderma reesei. Biotechnol Biofuels. 2014;7:129.

70. Steiger MG, Mach RL, Mach-Aigner AR. An accurate normalization strategy for RT-qPCR in Hypocrea jecorina (Trichoderma reesei). J Biotechnol. 2010;145:30-7.

71. Kubicek CP. Release of carboxymethyl-cellulase and $\beta$-glucosidase from cell-walls of Trichoderma reesei. Eur J Appl Microbiol Biotechnol. 1981:13:226-31.

72. Steiger M. Der Aktivator Xyr1 und seine Bedeutung für den Laktosemetabolismus von T. reesei. Diploma thesis, TU Wien. 2007.

73. Lorenz R, Bernhart SH, Zu Siederdissen CH, Tafer H, Flamm C, Stadler PF, et al. ViennaRNA Package 2.0. Algorithms Mol Biol. 2011;6:26. 